\title{
LOS PESCADORES TARDÍOS DE COBIJA, DEPÓSITOS DOMÉSTICOS Y ESTRATEGIAS DE SUBSISTENCIA.
}

\author{
Francisco García-Albarido y Victoria Castro ${ }^{2}$
}

\section{* Introducción}

\section{Resumen}

Abordamos el análisis de la economía doméstica de los grupos costeros de Cobija durante los periodos tardíos, discutiendo la consideración de actividades como la caza, pesca y recolección como estrategias de subsistencia estáticas a lo largo de la secuencia. Proponemos la existencia de grupos tardíos de pescadores especializados, dedicados a la generación de excedente pesquero destinado a comunidades locales y del interior de Atacama, gracias a la utilización sistemática de tecnologías como anzuelos metálicos y redes de algodón en una dinámica regional de fuerte integración económica. Desarrollamos una aproximación a sus depósitos domésticos, basándonos en los patrones depositacionales de los restos cotidianos como también en la funcionalidad de los instrumentos asociados, discutiendo los matices tardíos de estas prácticas económicas en relación a lo señalado por documentos escritos durante la colonización española de estos territorios.

Palabras claves: costa desértica - periodos tardíos - estrategias de subsistencia - depósitos domésticos - microhuellas de uso.

We approach the analysis of the domestic economy of the coastal groups of Cobija, considering hunting, fishing and gathering as dynamic subsistence strategies, with a particular configuration during the late precolumbian periods. We propose the existence of specialized fishermen, dedicated to generating a surplus of fish with help from certain technologies such as metal hooks and cotton nets. This surplus was distributed into the highlands and coastal communities in the context of a strong economic integration in Atacama during the late periods. We based our analysis ofthe domestic deposits in the study of the depositional patterns of daily remains and the functional analysis of the associated instruments or tools. Furthermore, we discuss the nuances of their economic practices in relation to the documents written during the colonization of these territories.

Key words: Atacama coast - late precolumbian periods - domestic economy - domestic deposits - microwear traces.

Recibido: septiembre 2013. Aceptado: abril 2014.
Los grupos de la costa de Atacama desarrollaron estrategias de subsistencia basadas en la caza, la pesca y la recolección desde el periodo Arcaico en adelante (Llagostera 1992); no obstante, dichas prácticas económicas no debieran ser consideradas estáticas puesto que diversos contextos históricos influyeron en su desarrollo. Los depósitos domésticos nos permitieron un acercamiento a dichas estrategias y sus transformaciones, al poder comparar tipos de restos y sus asociaciones en una perspectiva diacrónica orientada a la comprensión de las singularidades de las prácticas económicas de los grupos de la costa desértica de Cobija durante los periodos tardíos (900-1536 DC).

Nuestra aproximación consideró principalmente el análisis de los patrones de descarte de restos alimenticios e instrumentos, ahondando en la forma en que estos últimos fueron utilizados, lo que fue una vía para establecer con cierta particularidad las prácticas económicas de los grupos tardíos que habitaron Cobija. Para lo anterior consideramos depósitos domésticos de los periodos Arcaico, Intermedio Tardío y Tardío, los que representan las ocupaciones mejor conocidas del área de estudio del proyecto Fondecyt 1100951 "Del Periodo Formativo al Tardío en la costa de Antofagasta. Cronología e interrelaciones con las tierras altas" (2010-2014), así como de un proyecto anterior. ${ }^{3}$

De igual forma, el acercamiento arqueológico a nuestro problema de estudio y sus principales resultados fueron

\footnotetext{
1 Programa de Doctorado Universidad de Tarapacá - Universidad Católica del Norte (UTA-UCN). 5 de Abril 127, Viña del Mar, CHILE. Email: info@arqueologiachile.cl

2 Universidad Alberto Hurtado. Las Perdices 575, Santiago, CHILE. Email: vcastror53@gmail.com
} 
discutidos a la luz de las referencias escritas sobre las prácticas económicas de los grupos que habitaron esta parte de la costa de Atacama. La discusión entre evidencias arqueológicas y menciones etnohistóricas nos habilitó para describir las estrategias de subsistencia tardías, identificándose una serie de transformaciones asociadas a un contexto regional con mayor integración económica, migraciones al curso inferior del río Loa, aumento del caravaneo e intensificación de la producción excedentaria agrícola y también pesquera (Castro 2001; Uribe y Carrasco 2002; Berenguer 2004; Uribe y Adán 2005).

\section{* Estrategias de subsistencia, depósitos DOMÉsticos y LA COSTA dE ATACAMA}

Los depósitos domésticos pueden considerarse el registro arqueológico de actividades cotidianas reiteradas (Souvatzi 2008; Tringham 2001), tanto de subsistencia como artesanales (Earle 1994), incluyendo la producción, la distribución y el consumo (Nash 2009). Dichas actividades serían obra del grupo co-residente en un área habitacional no limitada al interior de las viviendas (During y Marciniak 2006). Estos depósitos presentarían asociaciones significativas entre distintos tipos de evidencias, por ejemplo, entre restos alimenticios y los instrumentos usados en su procesamiento, permitiendo una aproximación a las prácticas económicas desde la producción al consumo (Earle 1994; Lynne 1997; Stanish 1997; Tringham 2001; Andrefsky 2008; Souvatzi 2008; Field et al. 2010).

Por su parte, en los depósitos domésticos de las denominadas bases residenciales se encuentran frecuentemente evidencias de manufactura y uso de diversos tipos de instrumentos (De Souza 2003; Méndez 2007:55). El análisis del uso de los instrumentos también permite obtener valiosa información sobre las prácticas económicas de un grupo a través de la identificación de distintos tipos de instrumentos y de sus formas de utilización, lo que configura una estructura tecnológica determinada (Torrence 1989). La funcionalidad de un instrumento representa la solución a una necesidad práctica; al cambiar las prácticas

\footnotetext{
3 Proyecto FONDECYT 1050991: "El desierto costero y sus vinculaciones con las tierras altas. De Cobija a Calama" (2005-2008). Victoria Castro, Carlos Aldunate, Varinia Varela y Patricio Núñez.
}

económicas y sus respectivos requerimientos, resultará bastante probable una reconfiguración de la mencionada estructura (Elías 2008: 45; Nash 2009: 207). ${ }^{4}$

Los sistemas tecnológicos no debieran ser estudiados sin considerar los contextos socio-culturales en los que se originaron (Jackson 2003: 48). La tecnología correspondería al resultado dinámico de la interacción entre variables económicas, ideológicas, políticas y ambientales, entre otras (Elías 2008: 45). En específico, la tecnología lítica habría sido creada, reproducida o modificada en función del mencionado contexto, atendiendo a los cambios en las estrategias de subsistencia y sus requerimientos prácticos a lo largo de la secuencia (Earle 1994; Lynne 1997; Allison 1998; Tringham 2001; During y Marciniak 2006; Souvatzi 2008; Nash 2009). En nuestro caso, hemos desarrollado un análisis de los tipos de instrumentos líticos y sus modos de utilización, considerando sus principales asociaciones con otros tipos instrumentales y restos alimenticios. Ahora bien, ¿cuál es el contexto regional en el que los grupos costeros estuvieron inmersos durante los períodos tardíos?

Los grupos que habitaron Cobija durante el Intermedio Tardío habrían conservado las estrategias tradicionales fundadas en la pesca, la caza y la recolección, aunque incorporando un notorio intercambio de productos con los grupos de las tierras altas de Atacama (Castro 2001; Aldunate et al. 2008). Los principales depósitos domésticos del área presentaron consistentes evidencias cerámicas de San Pedro y el Loa en asociación con restos alimenticios principalmente de origen marino, registrándose fragmentos de los tipos Ayquina, Dupont, Turi Rojo Revestido y Turi Rojo Alisado. Por el contrario, la cerámica de los Valles Occidentales resultó menos frecuente, siendo registrada en Caleta del Fierro y en Cobija 24 , en asociación con cerámica del Loa y con la denominada cerámica Copaca Alisado Burdo (Varela 2009). De igual modo, varios depósitos domésticos presentaron cerámica del periodo Inca en asociación con los mencionados tipos del Intermedio Tardío, mientras otros

\footnotetext{
4 Por ejemplo, ante el aumento del sedentarismo en un grupo de alta movilidad, serían esperables nuevas respuestas tecnológicas cambiando la configuración de su estructura, aunque en algunos casos estas transformaciones pueden estar representadas por sutiles cambios en las frecuencias relativas más que en los tipos utilizados (Elías 2008: 47).
} 
evidenciaron cerámicas de las tierras altas del Loa e incluso del actual altiplano boliviano. Lo anterior permitió postular una fuerte interacción en Cobija entre los grupos costeros y del interior durante los periodos tardíos (Aldunate et al. 2008).

No obstante, en los Andes Centro Sur el contacto entre grupos de tierras altas y costa se habría producido por lo menos desde el $8000 \mathrm{AC}$, contemplando el intercambio de recursos y/o la ocupación directa de ciertas áreas de productividad secundaria (Núñez y Dillehay 1995: 158). Desde el 900 AC y gracias al desarrollo de caravanas más especializadas y regulares, las economías costeras se habrían basado tanto en recursos marinos como de intercambio, incorporando sistemáticamente los vegetales cultivados a la dieta (Núñez y Dillehay 1995: 160). Sin embargo, este proceso de complementariedad se habría intensificado notoriamente desde el período Intermedio Tardío en adelante (Castro 2001; Aldunate et al. 2008). Lo anterior habría acontecido en diversas regiones de los Andes Centro Sur contemplando el incremento de las prácticas de intercambio en asociación con una superproducción excedentaria de alimentos, la consolidación de economías agroganaderas y notorios cambios sociales (Berenguer 2004; Uribe y Adán 2005).

Las comunidades que habitaron Cobija durante los periodos tardíos habrían participado activamente de un contexto regional económicamente integrado con los grupos del interior de Atacama (Castro 2001; Aldunate et al. 2008). Esta fuerte integración de la costa como parte de Atacama habría complementado crecientemente las tradicionales estrategias de subsistencia basadas en la caza, pesca y recolección marina con recursos externos (Llagostera 1992: 91), destacando el consumo de vegetales cultivados en los contextos domésticos de Cobija (Castro 2010). Por su parte, en las tierras altas de la Subárea Circumpuneña, las transformaciones económicas acontecidas durante los periodos tardíos, han evidenciado una fuerte relación con transformaciones tecnológicas, especialmente en los conjuntos de instrumentos líticos (Carrasco 2002: 33; Hocsman 2006: 59; Méndez 2007). La intensificación de las prácticas agrícolas se manifiesta en mayores frecuencias de palas líticas, azadas, morteros y manos de moler (Uribe y Carrasco 1999; Hocsman 2006; Elías 2008). En consecuencia, resulta factible suponer que una transformación importante en las estrategias de subsistencia de las comunidades costeras, conlleve una transformación en la tecnología de obtención y procesamiento de alimentos (tipo y función).

De esta forma, si la mencionada interacción estuvo asociada a un cambio notorio en las estrategias de subsistencia de los grupos costeros, derivado de una mayor disponibilidad de alimentos vegetales (intercambiados y/o cultivados), las evidencias tecnológicas constituirían indicios del grado de transformación que esto significó, mientras que en el caso contrario, éstas podrían constituir evidencia indirecta de la continuidad de las tradicionales prácticas de subsistencia marina. Nos preguntamos, ¿cuáles son los indicios arqueológicos de dichas transformaciones?, ise reducen a la presencia de restos vegetales cultivados o comprometen también a la propia estructura tecnológica? A continuación explicaremos la metodología empleada para responder estas preguntas desde el estudio de los depósitos domésticos.

\section{* Metodología, sitios y muestra analizada}

Nuestro análisis consideró principalmente los restos alimenticios e instrumentales en términos depositacionales y en perspectiva comparativa. La intensidad en la depositación de cierto tipo de evidencia en un estrato determinado, fue calculada a través de la frecuencia de aparición por volumen excavado, lo que nos permitió comparar índices en depósitos de diversos periodos y comprender asociaciones significativas entre distintos tipos de restos (García-Albarido 2012). Gracias a este trabajo pudimos obtener un panorama general de los depósitos domésticos en cuanto a los tipos de restos más intensamente depositados en determinado momento y a sus asociaciones con otros. Esta metodología fue aplicada tanto a depósitos domésticos arcaicos como de los períodos tardíos, considerando en el primer caso, sitios como Copaca 1 o Guasilla 2 (García-Albarido 2012), cuya comparación con los segundos nos permitió evidenciar las transformaciones tardías que presentamos en las siguientes páginas.

De manera paralela, la aproximación a las transformaciones en las estrategias de subsistencia fue complementada con un análisis comparativo de la estructura tecnológica lítica, considerando tanto la de grupos arcaicos como 
tardíos e identificando tipos de instrumentos y modos de uso. La funcionalidad práctica de un instrumento corresponde a su modo de utilización, relacionándose a su morfología y a las estrategias particulares de explotación de recursos en la que éste participó (Andrefsky 2008:4). El análisis funcional de los instrumentos líticos permitió interpretar su forma de uso (Martínez 2002: 118), superando los sesgos inherentes a la utilización de tipologías morfológicas para interpretar funcionalidades. Éstas corren el riesgo de desconocer el hecho de que no todos los artefactos con la misma forma tuvieron la misma función (Fernández 2010: 153). El análisis de microhuellas constituye uno de los principales métodos de interpretación y determinación funcional de los instrumentos líticos, para lo que se requiere un aumento entre 40 y 100x (Pérez 2008: 198). Las microhuellas corresponden a alteraciones plásticas de la superficie de las rocas, originadas durante el uso del instrumento lítico por factores entre los que se cuentan presión, fricción y aumento de temperatura (Martínez 2002: 112). En nuestro caso usamos un aumento de $40 x$ mientras que las microhuellas observadas fueron interpretadas en función de los resultados obtenidos en réplicas experimentales usadas bajo condiciones controladas (García-Albarido 2012).

El estudio de la estructura tecnológica lítica nos permitió un acercamiento crítico a los tipos de instrumentos y sus formas de utilización, mientras que sus asociaciones y distribución en los depósitos nos posibilitaron obtener interesantes datos respecto a transformaciones tardías en las estrategias de subsistencia. Finalmente, estas inferencias arqueológicas fueron confrontadas con las menciones escritas sobre prácticas económicas hechas por los europeos durante la invasión y colonización temprana de la costa desértica, permitiéndonos discutir el panorama basado en las evidencias arqueológicas y sugerir algunas hipótesis para los períodos tardíos. De esta manera, varias fuentes de información fueron utilizadas para generar una aproximación a los depósitos domésticos y a las estrategias de subsistencia que los originaron. En el presente artículo nos centraremos en cuatro sitios arqueológicos de Cobija y sectores aledaños, los que representan los principales asentamientos del área durante los periodos tardíos (Figura 1).

El sitio arqueológico Guasilla 2, ubicado en una punta rocosa al sur de Cobija, corresponde a un extenso con- chal con una dispersión superficial de evidencias en un área superior a los $5000 \mathrm{~m}^{2}$. Las excavaciones ${ }^{5} \mathrm{de}-$ mostraron una amplia secuencia ocupacional en uno de los dos sectores del sitio (sector b), con fechados radiocarbónicos entre los 5550 y $5240 \mathrm{AP}$ en las capas inferiores (Tabla 1), así como ocupaciones del periodo Intermedio Tardío en las capas superiores. El otro sector (a), presentó depósitos domésticos con fechas posteriores al 955 AP. Por otra parte, el extenso conchal Caleta del Fierro 2 presentó una extensión superficial aproximada de $10000 \mathrm{~m}^{2}$, que incluyó un sector funerario y otro con estructuras circulares. Este sitio evidenció una importante ocupación desde el Intermedio Tardío en adelante, con cerámica Inca, Ayquina y Dupont. Las excavaciones revelaron un depósito doméstico extenso aunque menos profundo, ${ }^{6}$ situación que motivó el desarrollo de recolecciones superficiales sistemáticas.

El sitio arqueológico Cobija i Norte (Cobija $1 \mathrm{~N})$, también correspondiente a un denso conchal, se encuentra emplazado sobre la segunda terraza, en las cercanías de una de las aguadas de la localidad (Castro et al. 2012). Tanto en excavación ${ }^{7}$ como recolección superficial se obtuvieron fragmentos cerámicos correspondientes a los periodos tardíos de Atacama, mientras los fechados radiocarbónicos disponibles arrojan un rango aproximado que comprende entre el 720 y el 400 AP. Este sitio fue mencionado por Cruz y Bravo (1980) y Bittmann 1983, quienes indicaron la existencia de ocupaciones prehispánicas tardías e históricas coloniales. Por su parte, Cobija 24 corresponde a otro conchal, situado también en las inmediaciones de la anterior aguada, donde las excavaciones evidenciaron altas frecuencias de material orgánico, restos cerámicos prehispánicos e históricos. ${ }^{8}$ Los fechados radiocarbónicos realizados señalaron fechas aproximadas comprendidas entre el 830 y $700 \mathrm{AP}$ para algunos depósitos domésticos.

\footnotetext{
5 Se excavaron cuatro unidades de $1 \mathrm{~m}^{2}$, alcanzándose profundidades máximas de 1,20 m.

6 Se excavaron siete unidades de distintas dimensiones, alcanzándose profundidades máximas de $50 \mathrm{~cm}$.

7 Se excavó una unidad de 1,05 x 1,15 m, donde se alcanzó 1,40 m de profundidad.

8 Se excavó una unidad de $1 \mathrm{~m}^{2}$, registrándose nivel estéril a 1,10 m de profundidad.
} 


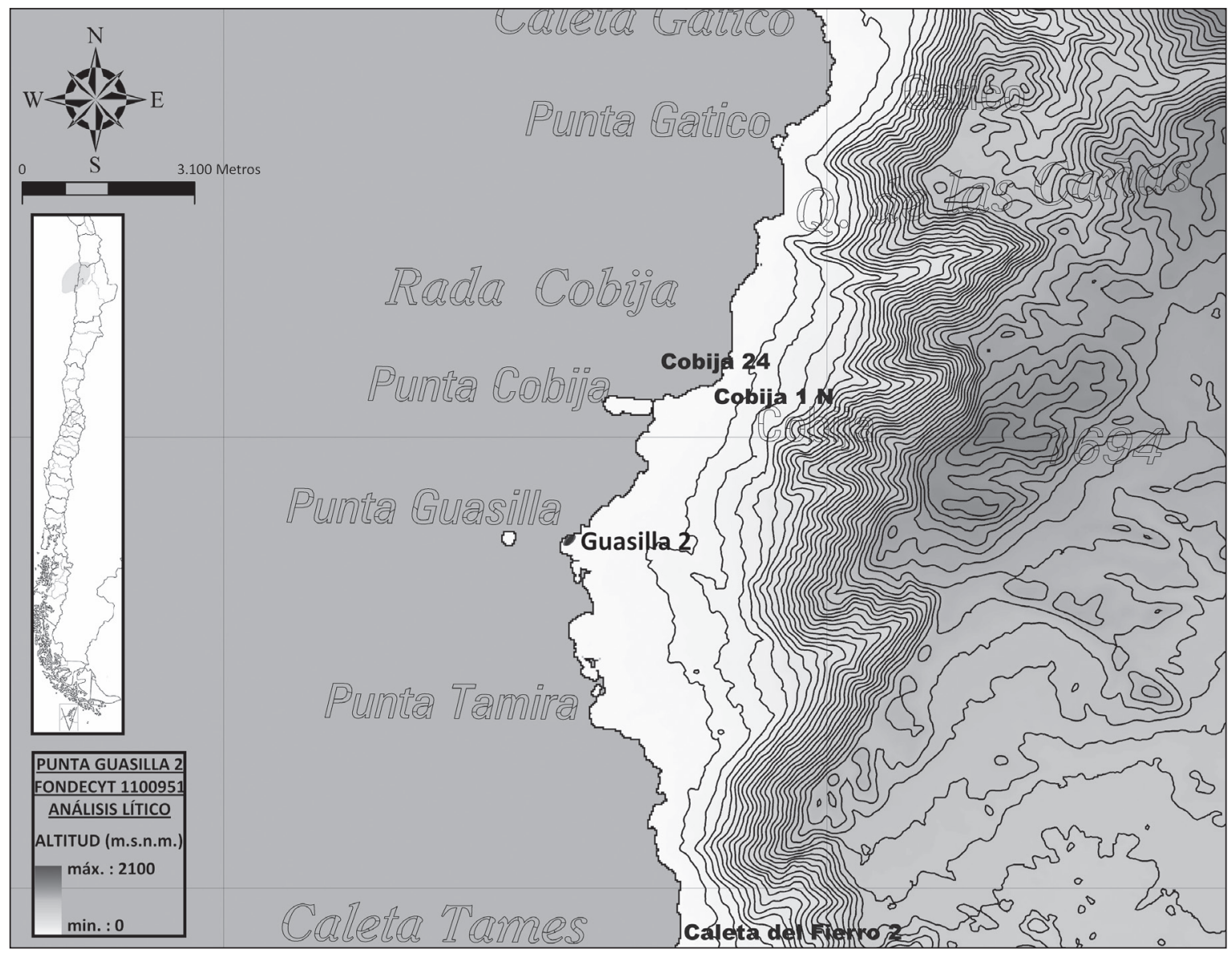

Figura 1. Mapa de los sitios arqueológicos analizados.

\begin{tabular}{|c|c|c|c|c|c|c|}
\hline \multirow{2}{*}{ Laboratorio } & \multirow{2}{*}{ Sitio } & \multirow{2}{*}{$\begin{array}{l}\text { Edad C14 con- } \\
\text { vencional }\end{array}$} & \multirow{2}{*}{ \pm} & \multicolumn{3}{|c|}{ Cal AD 10 (shcalo4.14c) } \\
\hline & & & & Mín. & Máx. & Prob. \\
\hline Beta-247640 & Cobija 24 & 600 & 40 & 1389 & 1422 & 0,7 \\
\hline Beta-247641 & Cobija 24 & 830 & 40 & 1222 & 1272 & 1 \\
\hline Beta-226031 & Cobija $1 \mathrm{~N}$ & 390 & 40 & 1571 & 1622 & 0,5 \\
\hline Beta-226032 & Cobija 1N & 330 & 40 & 1509 & 1580 & 0,7 \\
\hline Beta-226035 & Cobija $1 \mathrm{~N}$ & 640 & 40 & 1316 & 1355 & 0,7 \\
\hline Beta-226036 & Cobija ıN & 690 & 40 & 1348 & 1387 & 0,6 \\
\hline
\end{tabular}

Tabla 1. Fechados radiocarbónicos de sitios tardíos, calibrados con software Calib 611 (Stuiver y Reimer 1993), curva de calibración del Hemisferio Sur SHCalo4 (Mc Cormac et al. 2004). 


\begin{tabular}{|c|c|c|c|c|c|c|c|c|c|c|c|c|c|c|}
\hline Sitio & Unidad & Capa & Fecha AP & Vol. $\left(\mathrm{m}_{3}\right)$ & Desechos & $\begin{array}{c}\text { Puntas } \\
(\mathrm{e} / \mathrm{f})\end{array}$ & Raspador & Raedera & Cuchillo & Biface & Sobador & $\begin{array}{l}\text { Sob./ } \\
\text { Perc. }\end{array}$ & $\begin{array}{l}\text { A/ } \\
\text { Pas. }\end{array}$ & Pesas \\
\hline \multirow{4}{*}{ Cobija 24} & 1 & Total & & 1.1 & 0.015 (69) & & & & & & & & & \\
\hline & 1 & 1 & & 0.46 & $\begin{array}{c}0.0069 \\
(66)\end{array}$ & & $0.23(2)$ & & & & & & & \\
\hline & 1 & 2 & $\begin{array}{c}700(+/- \\
40)\end{array}$ & 0.34 & $0.34(1)$ & $0.34(1)$ & & & & & & & & \\
\hline & 1 & 3 & $\begin{array}{c}830 \\
(+/-40)\end{array}$ & 0.30 & $0.15(2)$ & $0.30(1)$ & & & & & & & & \\
\hline \multirow{6}{*}{ Cobija $1 \mathrm{~N}$} & 1 & Total & & 1.19 & $\begin{array}{c}0.00212 \\
(561)\end{array}$ & & & & & & & & & \\
\hline & 1 & 1 & $\begin{array}{c}430(+/- \\
40)\end{array}$ & 0.416 & $\begin{array}{c}0.0060 \\
(69)\end{array}$ & & $0.104(4)$ & & & & & & & \\
\hline & 1 & 2 & $\begin{array}{c}690 \\
(+/-40)\end{array}$ & 0.122 & $0.040(3)$ & & & & & & & & & \\
\hline & 1 & 3 & & 0.117 & $\begin{array}{c}0.0035 \\
(33)\end{array}$ & $0.117(1)$ & & & & & & & & \\
\hline & 1 & 495 & $\begin{array}{c}720(+/- \\
40)\end{array}$ & 0.467 & $\begin{array}{c}0.0010 \\
(465)\end{array}$ & $0.155(3)$ & $0.093(5)$ & $0.155(3)$ & $0.467(1)$ & & & & & \\
\hline & 1 & 6 & & 0.068 & $0.068(1)$ & & & & & & & & & \\
\hline \multirow{4}{*}{ Guasilla 2} & 4 & Total & & 0.21 & $0.011(19)$ & & & & & & & & & \\
\hline & 4 & $1(a+b)$ & & 0.16 & $0.01(16)$ & & & & & & $0.16(1)$ & $0.16(1)$ & $\begin{array}{c}0.16 \\
(1)\end{array}$ & $\begin{array}{c}0.08 \\
(2)\end{array}$ \\
\hline & 4 & Ic & & 0.05 & $0.016(3)$ & $0.05(1)$ & & & & & $0.05(1)$ & & & \\
\hline & 4 & 5 & & 0.27 & $\begin{array}{c}0.0019 \\
(141)\end{array}$ & $0.03(7)$ & & $0.13(2)$ & $0.09(3)$ & $\begin{array}{l}0.13 \\
(2)\end{array}$ & & & & \\
\hline
\end{tabular}

Tabla 2. Frecuencia de aparición por volumen excavado para instrumentos (e/f: entera/fragmento; sob./perc.: sobador/percutor; a/pas: alisador/pasivo).

\section{* Arqueología de los depósitos DOMÉsticos EN COBIJA}

Los contextos domésticos de periodos tardíos en la costa desértica manifiestan fuertes prácticas pesqueras, con abundantes restos ictiológicos e instrumentos relacionados (Sanhueza 1985: 48). En Cobija, las evidencias tardías de estas prácticas se relacionaron tanto con restos ictiológicos, como con lienzas y cordeles, anzuelos metálicos e instrumentos líticos (Castro 2010; Castro et al. 2012). En primer lugar, las actividades de pesca quedaron evidenciadas en el registro por pesas líticas. En Guasilla 2 , ciertos depósitos tardíos mostraron altísimas frecuencias de aparición, con una pesa cada $0.08 \mathrm{~m}^{3}$ o cada 0.19 $\mathrm{m}^{3}$ excavados (Tabla 2), así como un anzuelo de cobre significativamente asociado con éstas. Asimismo, en Cobija $1 \mathrm{~N}$ apareció una barba ósea para anzuelo compuesto en un depósito fechado en torno al 1300 DC (Santander 2011). En estos depósitos domésticos fueron recuperados abundantes restos de lienzas y cordeles, principalmente hechos con algodón. En Cobija $\mathrm{nN}$ se registraron fragmentos de lienzas y redes usados en actividades pesqueras (Cases 2009: 5). En Cobija 24 aconteció una situación equivalente, mientras que en Caleta del Fierro 2 fueron encontradas lienzas de pesca de algodón ( $\mathrm{Ca}$ ses 2009: 8). En este sitio el sector habitacional presentó buena proporción de hilados de probable uso pesquero (Cases 2009: 6), mientras que en Guasilla 2 también se 
los encontró en diversas unidades. En consecuencia, buena parte de los depósitos tardíos evidenciaron asociaciones significativas entre diversos instrumentos utilizados en actividades pesqueras.

Ahora bien, en asociación recurrente con el mencionado instrumental pesquero, los depósitos tardíos también presentaron altas frecuencias de restos ictiológicos. Cobija $1 \mathrm{~N}$ mostró frecuencias muy significativas en depósitos fechados entre el 1300 y 1500 DC (Castro 2010), recuperándose un resto ictiológico cada $0.0002 \mathrm{~m}^{3}$ excavados (Torres 2008). El jurel (Trachurus symmetricus), correspondió a la especie más frecuente, con una curva de tallas que sugirió el uso de redes de pesca. Curiosamente, el depósito con mayores frecuencias de instrumentos y desechos líticos presentó escasos restos ictiológicos sin evidencias de instrumental pesquero. Por su parte, en Cobija 24 un depósito originado en torno al 1300 DC entregó las mayores frecuencias de restos ictiológicos, recuperándose además un fragmento de red de pesca (Torres 2008). Nuevamente, los depósitos con mayores frecuencias de evidencias líticas volvieron a presentar menores frecuencias de restos ictiológicos. En Caleta del Fierro 2 las mayores frecuencias de restos óseos de lenguado y jurel se relacionaron con cerámica de periodos tardíos (Torres 2008). Por su parte, en Guasilla 2, ciertos depósitos con bajas frecuencias de evidencias líticas también presentaron altas frecuencias de restos ictiológicos, principalmente de jurel (90\%), con un resto cada 0.0006 o cada $0.0007 \mathrm{~m}^{3}$ excavados (Jimena Ruz, comunicación personal, 2011). En consecuencia, resultó bastante evidente que las ocupaciones humanas tardías desarrollaron intensas actividades de pesca caracterizadas por la generación regular de depósitos con altas frecuencias de restos ictiológicos (a diferencia de algunos arcaicos), manifestando también una especialización en determinadas especies marinas y en la captura con redes de algodón (García-Albarido 2012: 106).

De igual manera, en Cobija hemos observado una significativa asociación entre ocupaciones de periodos tardíos y la presencia de vegetales cultivados o nativos de otras localidades, situación no observada en depósitos arcaicos. En Guasilla 2, los restos vegetales se asociaron estrechamente con ocupaciones vinculadas a cerámica de periodos tardíos de las tierras altas atacameñas (Castro 2010). Los restos de cucurbitaceae fueron recuperados en forma de semillas, posiblemente relacionadas al consumo, pero también como pericarpios, utilizados probablemente como contenedores. Los restos de chañar (Geoffroea decorticans) y algarrobo (Prosopis sp.), fueron recuperados en todos los depósitos domésticos de estos periodos, pudiendo haber sido aprovechados como alimento, combustible y/o forraje. Asimismo, fueron registrados endocarpios de algodón (Gossypium s.p.), dando cuenta del arribo de dicha materia prima en estado natural. Los restos de maíz (zea mays), fueron observados en varios depósitos de periodos tardíos, frecuentemente asociados con algarrobo y chañar (Valentina Varas, comunicación personal, 2012). Adicionalmente, numerosos restos de madera del interior de la región, con extremos aguzados y funcionalidad desconocida, fueron recuperados en depósitos tardíos de Guasilla 2. Por su parte, en Cobija $1 \mathrm{~N}$ los depósitos tardíos evidenciaron algarrobo (Prosopis s.p.), traído desde localidades interiores (Castro 2010).

Por el contrario, si bien la recolección de moluscos en el intermareal rocoso correspondió a una dilatada estrategia de subsistencia basada en la obtención de recursos de fácil acceso (Peña et al. 2013), las frecuencias de aparición de este tipo de restos evidenciaron prácticas de menor intensidad durante los periodos tardíos. En Cobija $1 \mathrm{~N}$ los restos malacológicos presentaron bajas frecuencias en depósitos fechados en torno al 1350 DC (Marcela Lucero, comunicación personal, 2008), registrándose una situación equivalente en otros depósitos fechados entre el 1300 y 1600 DC (Castro 2010). En Caleta del Fierro 2 , los restos de tegula atra, concholepas y fisurellas, también presentaron bajas frecuencias en comparación con lo observado en depósitos arcaicos. Por su parte, en Guasilla 2 los depósitos originados durante los periodos tardíos también demostraron frecuencias notoriamente menores que las arcaicas. ${ }^{9}$ No obstante todo lo anterior, Cobija 24 presentó mayores frecuencias y variedad de especies, destacando tegula atra, concholepas y fisurellas. De este modo, a pesar de algunas excepciones, las estrategias tardías sugirieron una menor dependencia en la recolección de moluscos en comparación con los depósitos generados

9 Excepto en la capa n 5 de las unidades 3 y 4 , donde fueron identificados restos malacológicos en mayores frecuencias depositacionales. La ocupación que originó este depósito también produjo mayores frecuencias de restos líticos y de arqueofauna. 
por los cazadores y pescadores arcaicos del área (GarcíaAlbarido 2012: 106).

Tanto en tierra como en el mar, los pescadores tardíos continuaron cazando mamíferos, por lo que esta actividad siguió representando una estrategia de subsistencia en esta parte de la costa desértica (Sanhueza 1985; Castro 2010). Sin embargo, en los depósitos domésticos tardíos, los restos óseos de los animales obtenidos nos remitieron a prácticas selectivas, orientadas principalmente a la captura de otáridos y camélidos, aunque estos últimos en menor medida. Sus restos óseos fueron depositados en frecuencias variables, las que en términos comparativos generales resultaron bajas. Revisando lo registrado en los depósitos tardíos de los sitios que nos ocupan, se puede mencionar en primer lugar, los escasos restos óseos obtenidos en Cobija 24 correspondientes principalmente a otáridos, fócidos y camélidos (Cartagena 2008:3), mientras que en Guasilla 2 se recuperaron otáridos y en menor medida camélidos (Olguín 2011: 12). En este último sitio, donde los restos ictiológicos resultaron abundantes, los instrumentos líticos y los restos óseos de mamíferos resultaron escasos (Olguín 2011), situación que también fue observada en Cobija 24 (Cartagena 2008). En segundo lugar, los instrumentos de caza resultaron escasos, especialmente en lo que respecta a sus componentes confeccionados con materias primas de origen orgánico (p.e., óseas). Los depósitos domésticos de Cobija $1 \mathrm{~N}$ y Cobija 24 no los presentaron, mientras que únicamente fueron recuperadas dos barbas óseas en un depósito específico de Guasilla 2 (en asociación con mayores frecuencias de restos óseos y desechos de talla). En consecuencia, los grupos de pescadores tardíos depositaron restos de mamíferos en una frecuencia notoriamente menor que la observada en los depósitos arcaicos del área; sabemos que durante el período Arcaico, las actividades de cacería y faenamiento de presas estuvieron fuertemente basadas en la tecnología lítica (García-Albarido 2012). Entonces ¿cuál es el panorama observado para los periodos tardíos?

\section{* Tecnología lítica y funcionalidad TARDÍA COSTERA}

En Cobija, la tecnología lítica de períodos tardíos estuvo conformada por instrumentos con bordes filosos, tallados principalmente en materias primas silíceas, pero también por instrumentos expeditivos correspondientes a guijarros de andesita, los cuales fueron usados sistemáticamente en actividades de frotado abrasivo de otras superficies (Tabla 3). Los anteriores instrumentos fueron utilizados a lo largo de la secuencia ocupacional de esta parte de la costa desértica, representando una fuerte continuidad, no obstante lo cual los depósitos tardíos evidenciaron un notorio cambio: la virtual desaparición de la industria de guijarros de andesita con bordes filosos tallados, instrumentos frecuentemente utilizados durante el período Arcaico (García-Albarido 2012: 122). De igual modo, los desechos de talla, tanto en andesita como en sílice, redujeron notoriamente sus frecuencias de aparición, resultando virtualmente inexistentes los primeros. Las frecuencias de instrumentos tallados en sílice también resultaron notoriamente menores en comparación con dicho periodo, mientras que los desechos de sílice con talón facetado, evidencia indirecta del retoque de instrumentos bifaciales, tendieron a desaparecer en los depósitos domésticos tardíos. En Cobija dichos depósitos demostraron claramente una menor intensidad de talla y uso de instrumentos líticos en comparación con los de los periodos anteriores conocidos (García-Albarido 2012). No obstante lo anterior, fueron recuperados y analizados 177 instrumentos líticos, los que pasamos a revisar en términos tipológicos y funcionales.

En Guasilla 2 se recuperaron instrumentos completos, fragmentados o en proceso de talla. Los cantos rodados de andesita fueron frecuentemente utilizados a modo de sobadores, mientras que también encontramos cierta cantidad de alisadores pasivos, usados para friccionar y dar forma a otros materiales (Figura 2). Estos tipos morfológicos (sensu Orquera y Piana 1983) representaron en conjunto más de un tercio de los instrumentos recuperados en los depósitos domésticos del sitio, dando cuenta de la importancia de las tareas abrasivas realizadas. En paralelo, fue recuperado un conjunto de instrumentos de bordes filosos, demostrando una amplia variabilidad técnica comprendida entre lascados sumarios y retoques profundos (sensu Aschero [1974] 1983). Estos instrumentos quedaron representados por puntas líticas, las que entre fragmentos, preformas y puntas enteras sumaron casi un tercio de los tipos morfológicos. En específico, estas últimas correspondieron a puntas pequeñas pedunculadas con aletas y a una punta triangular apedunculada. Asimismo, fue recuperado un reducido conjunto de cuchillos líticos, varios de ellos con filo convergen- 


\begin{tabular}{|c|c|c|c|c|c|c|c|c|}
\hline \multirow{2}{*}{$\begin{array}{l}\text { Tipo morfológico } \\
\text { Biface }\end{array}$} & \multicolumn{2}{|c|}{ Guasilla 2} & \multicolumn{2}{|c|}{ C. Fierro 2} & \multicolumn{2}{|c|}{ Cobija 24} & \multicolumn{2}{|c|}{ Cobija 1} \\
\hline & 3 & $7,32 \%$ & 1 & $0,87 \%$ & o & & O & \\
\hline Cuchillo & 4 & $9,76 \%$ & 2 & $1,74 \%$ & O & & 1 & $5,88 \%$ \\
\hline Raedera & 2 & $4,88 \%$ & 5 & $4,35 \%$ & ० & & 3 & $17,65 \%$ \\
\hline Perforador & O & & 3 & $2,61 \%$ & o & & ० & \\
\hline Raspador & O & & 4 & $3,48 \%$ & 2 & $50,00 \%$ & 9 & $52,94 \%$ \\
\hline Punta & 2 & $4,88 \%$ & 3 & $2,61 \%$ & 2 & $50,00 \%$ & 4 & $23,53 \%$ \\
\hline Fragmento de punta & 8 & $19,51 \%$ & 3 & $2,61 \%$ & o & & o & \\
\hline $\begin{array}{l}\text { Fragmento preforma } \\
\text { punta }\end{array}$ & 3 & $7,32 \%$ & 14 & $12,17 \%$ & O & & o & \\
\hline Pesa para anzuelo & 3 & $7,32 \%$ & 1 & $0,87 \%$ & O & & ० & \\
\hline Alisador pasivo & 4 & $9,76 \%$ & 5 & $4,35 \%$ & O & & O & \\
\hline Sobador & 11 & $26,83 \%$ & 27 & $23,48 \%$ & o & & o & \\
\hline Percutor-sobador & o & & 27 & $23,48 \%$ & o & & o & \\
\hline Otros tipos & 1 & $2,44 \%$ & 8 & $6,96 \%$ & o & & o & \\
\hline Indeterminado & 0 & & 12 & $10,43 \%$ & o & & O & \\
\hline Total & 41 & $100 \%$ & 115 & $100 \%$ & 4 & $100 \%$ & 17 & $100 \%$ \\
\hline
\end{tabular}

Tabla 3. Tipos morfológicos de instrumentos líticos.

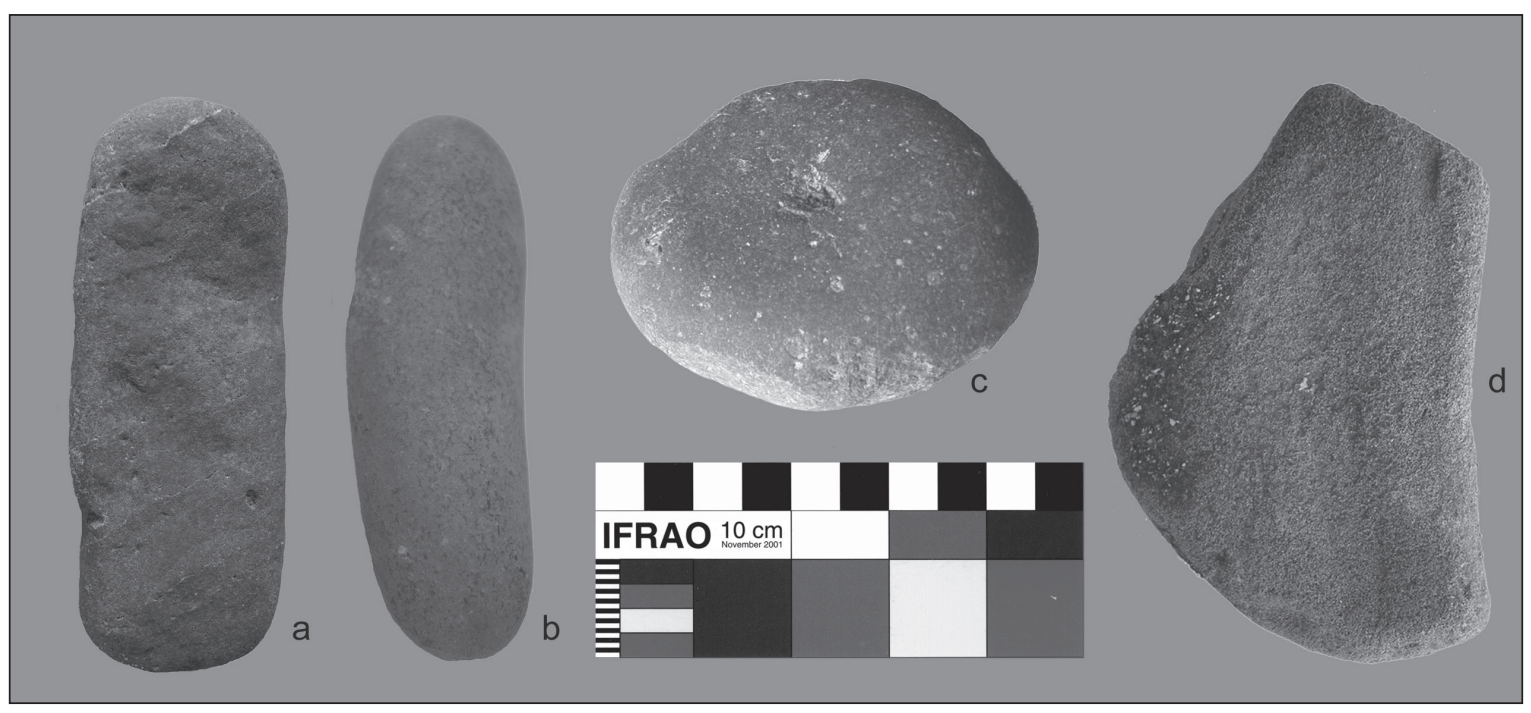

Figura 2. Sobadores a) GUAS2-U3-C5 y b) $\mathrm{CF}_{2}-\mathrm{CEM}-\mathrm{RS}$. Sobador percutor c) $\mathrm{CF}_{2}-\mathrm{CON}-\mathrm{RS}$ y sobador pasivo de arenisca d) GUAS2-U4-C1.

te en punta, algunos bifaces y dos raederas de filo lateral. La gran mayoría de estos instrumentos tallados presentaron una fuerte relación con depósitos puntuales (p. e., capa $n^{\circ} 5$ en unidad 4), encontrándose asociados con mayores frecuencias de desechos de talla y restos óseos. Otros depósitos, bastante más representativos que los anteriores para momentos tardíos, presentaron solamente sobadores y alisadores pasivos en asociación con pesas para anzuelos 


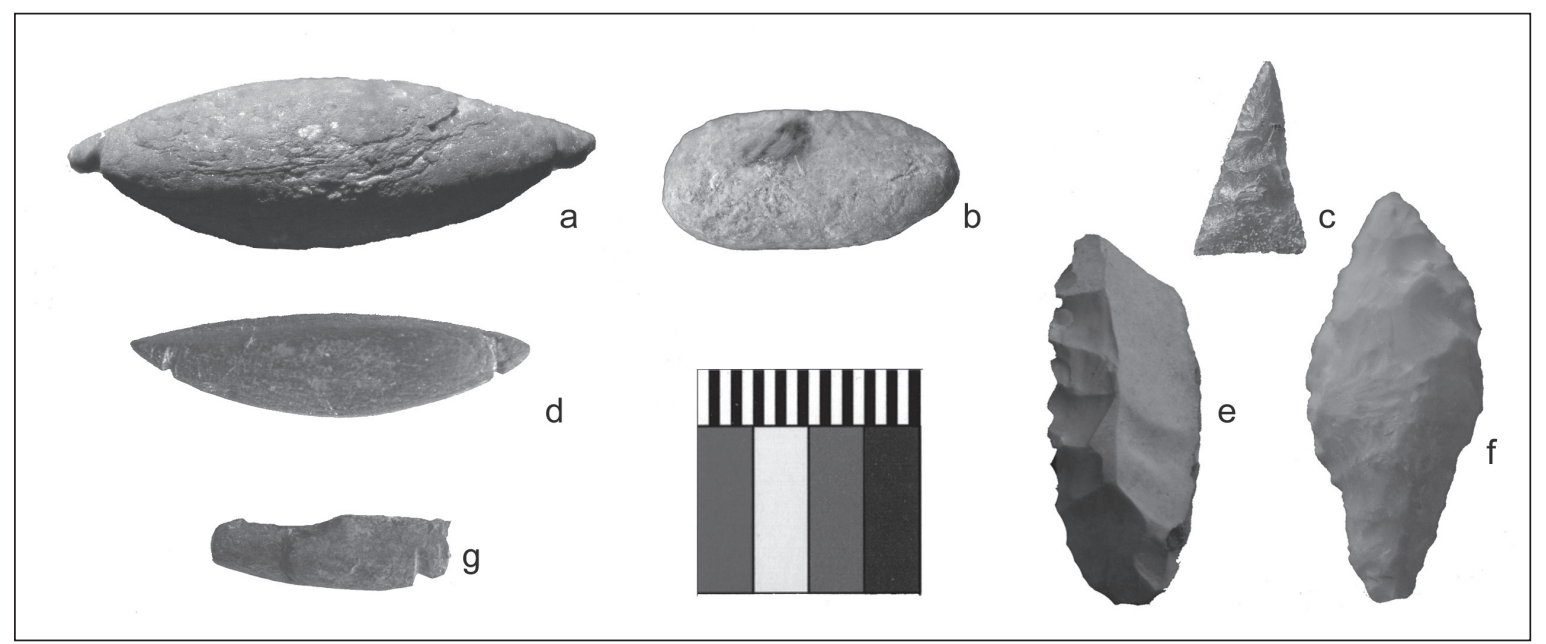

Figura 3. Pesas de pesca a) CF2-CEM-RS, b) GUAS2-U4-C1B, d) GUAS2-U33-C1 y g) GUAS2-U4-C1A. Raedera e) CF2-FUN-U1-C2. Puntas c) $\mathrm{CF}_{2}-\mathrm{U}_{1}-\mathrm{C}_{3}$ y f) $\mathrm{CF}_{2}-\mathrm{Ul}_{1}-\mathrm{C}_{1}$.

(Figura 3). En éstos, los desechos de talla resultaron virtualmente ausentes, dando cuenta de ocupaciones donde esta actividad no quedó plasmada de manera sistemática. Esta última situación contrastó notoriamente con los depósitos domésticos generados por las ocupaciones arcaicas (García-Albarido 2012).

Los instrumentos identificados en Caleta del Fierro 2 resultaron equivalentes a los del caso anterior. Los sobadores en guijarros de andesita resultaron muy frecuentes, aunque este sitio presentó una buena proporción de cantos rodados usados para percutir y sobar al mismo tiempo (funcionalidad múltiple). Por el contrario, los guijarros usados exclusivamente como percutores representaron una minoría (8). En los depósitos de este sitio también fueron recuperados alisadores pasivos en cierta proporción, instrumentos que sugieren una industria de otras materias primas, al presentar por ejemplo desgastes macroscópicos en surco. Por su parte, las puntas continuaron siendo un conjunto menos representado, recuperándose tanto preformas como fragmentos y puntas completas. Éstas últimas mantuvieron sus reducidas dimensiones, correspondiendo a puntas pedunculadas con y sin aletas, además de triangulares sin pedúnculo ni aletas. A diferencia de lo observado en depósitos arcaicos del área, las raederas y raspadores resultaron escasos, presentando principalmente filo lateral en el primer caso y perimetral en el segundo. Los perforadores y cuchillos resultaron todavía más escasos (entre otros tipos morfológicos).

Los depósitos domésticos excavados en Cobija 24 volvieron a evidenciar esta escasez de tecnología lítica, la excepción a lo anterior estuvo representada por un par de raspadores, recuperados en asociación con una mayor frecuencia de desechos de talla en un estrato específico. Por el contrario, en depósitos donde las actividades de talla lítica no quedaron mayormente plasmadas, fueron recuperadas dos puntas líticas pedunculadas con aletas pronunciadas. De esta forma, volvió a repetirse cierto patrón consistente en depósitos puntuales que concentran las evidencias líticas (desechos e instrumentos), intercalados en una mayoría donde éstas no tienen mayor representatividad. Por su parte, Cobija $1 \mathrm{~N}$ presentó un conjunto de raspadores tallados en sílice, asociados con raederas del mismo material y un cuchillo lítico, depositados en la misma capa con la mayoría de las puntas recuperadas. Nuevamente, determinados depósitos concentraron las evidencias de talla lítica e instrumentos de bordes activos filosos (p. e., unidad 1 capas $n^{\circ} 4$ y 5), abriendo la posibilidad de que correspondan a áreas específicas de actividad dentro del sitio, de que sean producto de ocupaciones de segmentos especializados en la caza, o bien que se trate de ambas juntas. Ahora bien icómo fueron utilizados los distintos tipos de instrumentos señalados? En los siguientes párrafos presentaremos los 


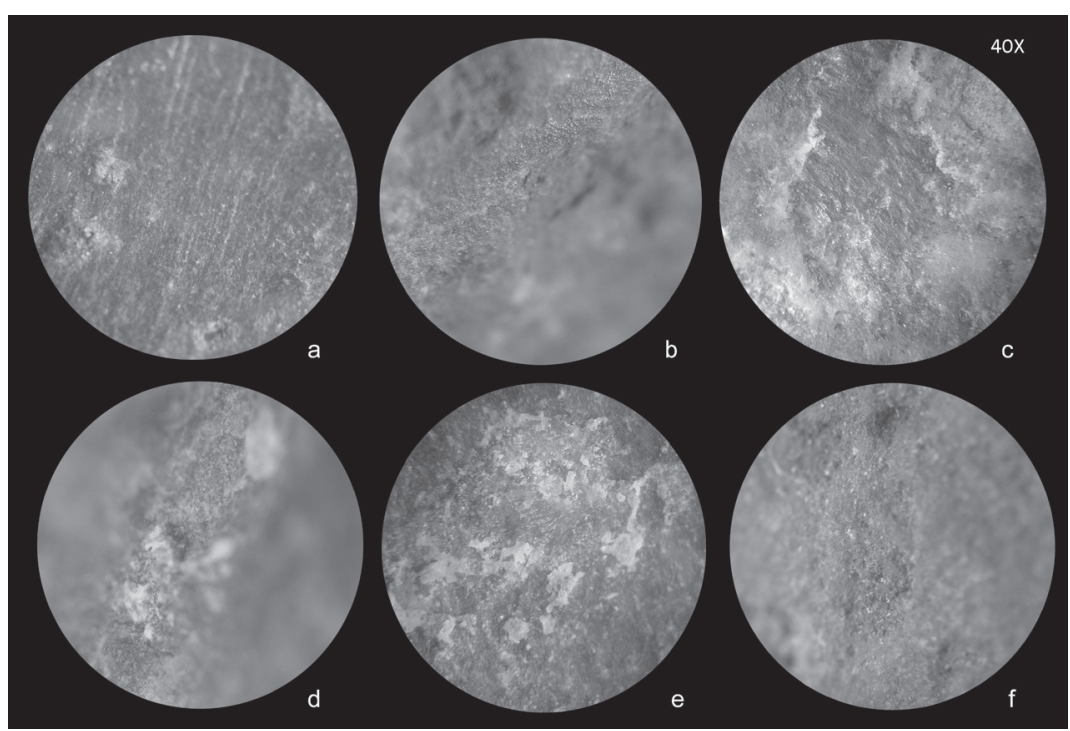

Figura 4. Superficies activas con estrías y adherencias originadas en actividades de frotado (registradas en instrumentos recuperados en depósitos tardíos).

\begin{tabular}{|l|c|c|c|c|}
\hline \multicolumn{1}{|c|}{ Microhuellas } & \multicolumn{2}{|c|}{ Caleta del Fierro 2 } & \multicolumn{2}{c|}{ Guasilla 2 } \\
\hline Frotado abrasivo & 31 & $34,83 \%$ & 9 & $20,93 \%$ \\
\hline Corte & 17 & $19,10 \%$ & 6 & $13,95 \%$ \\
\hline Indeterminadas & 13 & $14,61 \%$ & 5 & $11,63 \%$ \\
\hline Percusión & 7 & $7,87 \%$ & 2 & $4,65 \%$ \\
\hline Corte y raspado & 4 & $4,49 \%$ & 1 & $2,33 \%$ \\
\hline Raspado & 3 & $3,37 \%$ & 1 & $2,33 \%$ \\
\hline Perforación & 2 & $2,25 \%$ & 0 & $0,00 \%$ \\
\hline Desconche & 1 & $1,12 \%$ & 0 & $0,00 \%$ \\
\hline Sin microhuellas & 11 & $12,36 \%$ & 19 & $44,19 \%$ \\
\hline Total & $\mathbf{8 9}$ & $\mathbf{1 0 0} \%$ & 43 & $\mathbf{1 0 0} \%$ \\
\hline
\end{tabular}

Tabla 4. Microhuellas de uso identificadas.

resultados del análisis de microhuellas efectuado a instrumentos recuperados de Caleta del Fierro 2 y Guasilla 2 , sitios donde se obtuvieron los principales conjuntos de evidencias líticas tardías.

Nuestro análisis funcional consideró un importante conjunto de instrumentos en el caso de Caleta del Fierro $2^{10}$ (Tabla 4). Lo primero que queremos señalar es que en concordancia con los tipos morfológicos identificados, los

\footnotetext{
${ }^{10}$ Se dejaron fuera de observación las piezas con pátinas o erosionadas.
}

principales conjuntos de microhuellas de uso correspondieron a las de frotado abrasivo y corte (García-Albarido 2012). Por el contrario, aquellas relacionadas a actividades que requirieron percusión, raspado, perforación y abrasión pasiva, resultaron poco representadas en los instrumentos analizados. En los depósitos del sitio, las prácticas económicas más representadas se relacionaron con tareas de frotado abrasivo, observándose en las superficies activas de los sobadores, grupos de estrías rectas e inclusiones minerales con desgastes regulares. Estas evidencias fueron identificadas en cantos rodados de tamaños manipulables, sugiriendo tareas que requirieron frotadores activos (García-Albarido 2012). La mayoría de estos sobadores de andesita presentaron ciertas adherencias orgánicas amarillas (probablemente de origen animal) que en algunos casos se registraron asociadas con adherencias minerales rojizas (seguramente óxido de fierro) u orgánicas verdosas (de posible origen vegetal), todas emplazadas en estrecha relación con las estrías arriba referidas (en bordes y superficies activas). La identificación de dichas adherencias requiere de análisis especializados que nos permitirán afinar nuestra comprensión de las prácticas económicas a través de los materiales trabajados. A pesar de lo anterior, consideramos que las evidencias sugirieron importantes tareas de frotado de materiales blandos, en algunos casos en asociación con minerales pulverizados (Figura 4). 


\begin{tabular}{|c|c|c|c|c|c|c|c|c|c|c|c|c|c|c|}
\hline Sitio & Capa & Fecha & $\begin{array}{l}\text { Vol. } \\
\left(\mathrm{m}_{3}\right)\end{array}$ & Cortar & $\begin{array}{l}\text { Cortar/ } \\
\text { Raspar }\end{array}$ & Raspar & Frotado/a & F/A/P & Pesa & $\begin{array}{c}\text { Percu- } \\
\text { tir }\end{array}$ & F/P/A & $\begin{array}{c}\text { Pref. } \\
\text { Punta }\end{array}$ & Punta & Perforar \\
\hline \multirow{12}{*}{$\begin{array}{c}\text { Guasilla } \\
2 \\
\mathrm{U}_{4}\end{array}$} & $1(a+b)$ & & 0.16 & 0 & o & 0 & $0.16(1)$ & $\begin{array}{c}0.16 \\
(1)\end{array}$ & $\begin{array}{c}0.08 \\
(2)\end{array}$ & o & $\begin{array}{c}0.16 \\
(1)\end{array}$ & $0.08(2)$ & o & o \\
\hline & ic & & 0.05 & o & o & $\circ$ & o & o & o & o & o & $\circ$ & o & o \\
\hline & 2 & & 0.027 & o & $\circ$ & o & o & o & ○ & o & o & o & o & o \\
\hline & 3 & & 0.035 & 0 & o & o & 0 & 0 & 0 & o & 0 & 0 & o & o \\
\hline & 4 & & 0.032 & 0 & 0 & o & 0 & o & 0 & o & 0 & 0 & o & 0 \\
\hline & 5 & & 0.27 & $\begin{array}{c}0.04 \\
(6)\end{array}$ & $0.27(1)$ & o & 0 & o & o & $\circ$ & o & o & $\begin{array}{c}0.04 \\
(6)\end{array}$ & $0.27(1)$ \\
\hline & $6+7$ & 5240 & 0.04 & 0 & o & o & 0 & 0 & 0 & $\circ$ & o & o & $\begin{array}{c}0.02 \\
(2)\end{array}$ & $\circ$ \\
\hline & $8+9$ & & 0.28 & $\begin{array}{c}0.09 \\
(3)\end{array}$ & $0.14(2)$ & $\begin{array}{c}0.09 \\
(3)\end{array}$ & $0.28(1)$ & o & $\circ$ & $\begin{array}{c}0.28 \\
(1)\end{array}$ & o & $0.28(1)$ & o & o \\
\hline & 10 & & 0.04 & $\begin{array}{c}0.04 \\
(1)\end{array}$ & $0.04(1)$ & o & $\circ$ & o & o & $\circ$ & o & $\circ$ & $\circ$ & o \\
\hline & 11 & & 0.07 & $\begin{array}{l}0.07 \\
(1)\end{array}$ & o & o & $0.03(2)$ & o & o & $\circ$ & $\circ$ & o & $\begin{array}{c}0.07 \\
(1)\end{array}$ & 0 \\
\hline & 12 & & 0.15 & o & $\circ$ & $0.15(1)$ & $0.07(2)$ & $\circ$ & $\circ$ & $\circ$ & $\circ$ & $0.15(1)$ & $\circ$ & o \\
\hline & 13 & 5550 & Sin ref. & 4 & 1 & o & 3 & o & 0 & o & 0 & 0 & o & o \\
\hline
\end{tabular}

Tabla 5. Frecuencia de aparición de microhuellas de uso por volumen excavado en unidad 4 de Guasilla 2 (frotado/a: activo; f/a/p: frotador/activo/percutor; f/p/a: frotador/pasivo/aguzador; pref. punta: preforma de punta).

Por su parte, el conjunto anterior evidenció en una buena proporción que estos instrumentos también fueron usados para percutir (45,1\%, 14 casos) (García Albarido 2012). Deesta manera, en asociación con las microhuellas arriba descritas, fueron registradas oquedades generadas por impactos contra materiales más duros, inclusiones fracturadas con porciones ausentes y desportilladuras macroscópicas. Al menos la mitad de estas herramientas multifuncionales presentaron las mencionadas adherencias orgánicas amarillas, en algunos casos asociadas con las minerales rojizas y verdosas. En función de lo anterior, consideramos que muchos de estos sobadores se usaron para percutir materiales duros, como por ejemplo minerales rojizos, además de usarse para frotar materiales blandos. En términos generales, estos sobadores y sobadores percutores provinieron tanto de la superficie del sitio como de sus depósitos (en espacios internos y exteriores de las estructuras existentes). Finalmente, una minoría de guijarros fue utilizada exclusivamente como percutores, presentando las alteraciones arriba señaladas asociadas en dos casos a mineral pulverizado. ${ }^{11}$ En consecuencia, los grupos que ocuparon el sitio durante los periodos tardíos realizaron habitualmente actividades en las que se frotaron materiales relativamente blandos, percutiendo también otros más duros, en presencia de probables minerales pulverizados.

Asimismo, sus prácticas económicas requirieron de cierta proporción de instrumentos cortantes, registrándose grupos de estrías rectas, paralelas entre sí y respecto al filo, ubicadas diferencialmente en porciones reducidas del borde activo (García Albarido 2012). No se observaron facetas oblicuas generadas por los materiales duros, mientras que en un tercio de los casos se identificaron sustancias orgánicas adheridas sugiriendo el corte de materiales blandos (p.e., carne). Estas microhuellas fueron identificadas principalmente en raederas $(17,6 \%, 3$ casos), cuchillos, raclettes y raspadores (11,7\%, 2 casos

${ }^{11}$ Probablemente óxidos de fierro y cobre. 
respectivamente). Al igual que en el conjunto de instrumentos abrasivos y de percusión, la distribución comprometió tanto superficie como estratigrafía. En un pequeño conjunto de instrumentos pudimos identificar microhuellas ocasionadas por acciones de corte y raspado, evidenciando extremos filosos redondeados, grupos de estrías rectas, en sentido paralelo y oblicuo al filo (entre otras). Finalmente, los instrumentos con microhuellas exclusivas de raspado, representadas principalmente por grupos de estrías rectas, perpendiculares al filo, presentaron bajas frecuencias de aparición, señalando prácticas de corte más notorias durante épocas tardías.

Por su parte, la preeminencia de microhuellas derivadas de actividades abrasivas volvió a manifestarse en el caso de Guasilla 2 (García Albarido 2012). No obstante, aquellas originadas en tareas que requirieron corte continuaron ocupando el segundo lugar (Tabla 4). Tal como en el sitio de Caleta del Fierro 2, fueron seleccionados cantos rodados de andesita local, en tamaños fácilmente manipulables, para desarrollar tareas de frotado activo que generaron las ya mencionadas estrías paralelas. Estos frotadores presentaron, en casi la mitad de los casos, una significativa asociación entre sustancias orgánicas y minerales rojizas (emplazadas en relación con las estrías), mientras que la otra mitad evidenció en todos los casos a las primeras. En función de lo anterior, estos instrumentos sugirieron que fueron empleados en tareas de frotado sobre materiales blandos, usando en buena parte de los casos, mineral rojizo pulverizado.

En términos estratigráficos, estos instrumentos fueron depositados en determinadas capas, evidenciando depósitos domésticos donde presentaron altas frecuencias y otros donde no apareció ni un solo caso (Tabla 5). Por su parte, dos instrumentos fueron usados en tareas que requirieron una superficie pasiva donde frotar otros materiales, en un caso implicando la mencionada asociación con sustancias orgánicas y minerales. Este sitio presentó un énfasis diferencial en relación con las actividades de percusión, fuertemente plasmadas en Caleta del Fierro 2, si consideramos que en este caso, resultaron virtualmente ausentes.

Nuevamente, la industria de instrumentos tallados en sílice mostró una fuerte relación con actividades de corte, alcanzando casi un 25\% de los casos (García Albarido
2012). Las microhuellas identificadas correspondieron principalmente a conjuntos de estrías paralelas, emplazadas en sectores acotados de los bordes filosos y en estrecha asociación con las mencionadas adherencias orgánicas. La ausencia de alteraciones asignables a corte sobre materiales duros (p.e., óseos) nos volvió a sugerir trabajos sobre materiales blandos en un alto porcentaje de los casos ( $83 \%, 5$ casos). Los tipos morfológicos en los que fueron identificadas presentaron marcada variabilidad comprendiendo cuchillos, bifaces, puntas y raederas. Un instrumento presentó micro alteraciones relacionadas a su uso para cortar y raspar, situación equivalente para un caso usado en tareas de raspado, por lo que nuevamente las actividades de corte resultaron mucho más frecuentes. Finalmente, resulta importante destacar que la totalidad de los instrumentos usados para cortar y a excepción de uno usado para raspar, fueron recuperados de un mismo depósito doméstico (capa n 5 en unidad 4). Como ya fue señalado en un apartado anterior, esta capa además presentó altas frecuencias de desechos de talla y de restos óseos animales. Por el contrario, en el resto de los depósitos tardíos del sitio, distribuidos en cuatro unidades y dos sectores, las únicas microhuellas de uso registradas correspondieron a aquellas originadas en tareas de frotado abrasivo de materiales blandos.

En consecuencia, la gran mayoría de los depósitos domésticos de periodos tardíos demostraron intensas actividades de pesca asociadas con el consumo de vegetales (cultivados y recolectados), no evidenciándose el uso sistemático de instrumentos líticos de bordes filosos para cortar y/o raspar, así como tampoco altas frecuencias de restos malacológicos o de mamíferos apresados. Esta situación contrasta notoriamente con los depósitos domésticos arcaicos del área, donde los restos malacológicos y óseos presentaron altas frecuencias, mientras que las microhuellas de corte sobre materiales blandos se asociaron recurrente y significativamente a la desaparecida industria de guijarros tallados (García Albarido 2012). Por el contrario, los eventos relativamente intensos de cacería de mamíferos y recolección de mariscos -donde la talla de instrumentos líticos presentó cierta preponderancia, evidenciándose también menores frecuencias de restos ictiológicos-, solamente fueron registrados en depósitos tardíos puntuales y poco representativos en el área. Lo anterior sugiere la existencia de grupos de pescadores especializados desde al menos el 
periodo Intermedio Tardío en adelante (probablemente desde mucho antes), que generaron depósitos domésticos con una composición diferente que nos invita a problematizar una concepción simplista de sus estrategias de subsistencia (Garcia Albarido 2012).

\section{* Las pRÁcticas económicas de los indios PESCADORES CAMANCHACAS}

Los españoles describieron a los grupos nativos de la costa de Atacama fundamentalmente como comunidades de pescadores especializados, refiriéndose invariablemente a las comunidades locales como "yndios pescadores, pescadores uros, camanchacas pescadores" (Aldunate et al. 2010: 344; Castro et al. 2012: 108-110). Durante la conquista de Atacama, específicamente entre fines de la década de 1540 y la de 1550 , los españoles observaron la existencia de grupos especializados de pescadores y cazadores marinos, denominados indistintamente "géneros de pescadores" (Vivar [1558] 1966: 12).

La especialización laboral de ciertos segmentos sociales de pescadores y cazadores, también señalada por Bittmann (1983: 148), habría implicado en algunos casos el uso de redes para captura. Según las referencias, ciertos tipos de peces y mamíferos marinos fueron exclusivamente capturados por determinados grupos de pescadores y cazadores. Sobre sus propias tumbas fueron dispuestos los instrumentos que utilizaron en sus labores, así como los cráneos de sus presas:

"Los que matan lobos no matan otros peces, como habemos dicho, y los que matan toninas es en ejercicio. Así que cada género de pescador mata el género de pescado a que se aficiona y no otro; $y$ cuando mueren manda que encima de su sepultura pongan las calaveras y todos los instrumentos de pescar, ansí redes como harponcillos y anzuelos sin lengüeta" (Vivar [1558] 1966: 12).

Por su parte, los observadores españoles señalaron que durante la década de 1580, los pescadores nativos de la ensenada de Atacama, todavía mantenían un modo de vida tradicional, no habiendo sido bautizados, reducidos ni encomendados. En este contexto, la población nativa de Cobija habría entregado pescados a los caciques de Atacama, lo que podría representar un vínculo econó- mico tradicional con las autoridades étnicas del interior. Esta valiosa referencia señala también que dichos grupos no realizaban ninguna labor agrícola ni de recolección de recursos vegetales, basando la subsistencia grupal en el consumo de pescados en un contexto económico que todavía no había sido reorganizado por la colonización española:

"En la ensenada de Atacama, ques donde esta el puerto, hay cuatrocientos indios pescadores uros, que no son bautizados ni reducidos, ni sirven a nadie, aunque a los caciques de Atacama dan pescado en señal de reconocimiento. Es gente muy bruta, no siembran ni cogen y susténtanse de sólo pescado" (Lozano Machuca [1581] 1885: XXV, en Castro et al. 2012: 108).

Justamente fue su población originaria de pescadores y sus abundantes recursos marinos los que despertaron el interés de las autoridades coloniales por Cobija. De esta forma, en 1587 los españoles decidieron fundar oficialmente un asentamiento portuario llamado "Santa María Magdalena de Cobija" (Castro et al. 2012: 34). En dicho puerto, ciertos sacerdotes y encomenderos españoles aprovecharon hábilmente a los pescadores nativos para reorganizar un sistema de tributo de pescado, iniciándose en la década de 1590 un importante tráfico a las ciudades españolas del altiplano, por los tradicionales caminos precolombinos (Aldunate et al. 2010: 343). En consecuencia, la colonización española de esta parte de la costa de Atacama explotó hábilmente la riqueza pesquera y la experticia de pescadores especializados en la obtención de los recursos del Pacífico. No obstante lo anterior, ¿hasta qué punto esta situación pudo haber acontecido en épocas precolombinas tardías?

Los territorios y comunidades de esta parte de la costa de Atacama formaron parte del Tawantinsuyu, en un proceso histórico que incluso comprendió sacrificios en el contexto ritual de la capacocha, realizado en el santuario de altura costeño de cerro Esmeralda (Checura 1977). Asimismo, sabemos por datos etnohistóricos ciertos detalles de esta incorporación al Collasuyo, la que habría tenido también un probable interés en los recursos mineros locales. Por ejemplo, las referencias etnohistóricas señalan que los incas explotaron el mineral de plata de Huantajaya en las cercanías de Iquique antes que los españoles. De esta forma, la costa de Atacama habría estado sujeta al noble Chuchi o Colla Capac, conformando 
una provincia que además habría incluido el área de los Chichas y de Arequipa (Castro et al. 2012: 106):

"Tenía Chuchi Capac opresas y sujetas más de ciento y setenta leguas de norte a sur, o como el se nombraba Capac o Colla Capac, desde veinte leguas del Cuzco hasta los Chichas y todos los términos de Arequipa y la costa de la mar hacia Atacama y las montañas sobre los Musos" (Sarmiento de Gamboa [1572] 1988, en Zanolli 2005: 58).

En función de esta narrativa, consideramos bastante probable que durante la conquista de esta parte de la costa desértica, específicamente en las décadas anteriores a la efectiva colonización de estos territorios, ciertas prácticas económicas descritas para los grupos costeros hayan sido muy similares a las desarrolladas durante el Tawantinsuyu (Castro et al. 2012: 108). En específico, nos referimos al probable tributo de pescado a los curacas de Atacama, situación observada antes del proceso de reorganización económica colonial y aculturación evangelizadora, desarrollado sistemáticamente desde la fundación de Santa María Magdalena en adelante. De todas formas, el transporte de productos marinos al interior, ya sea en un contexto de tributación o de intercambio más bien simétrico, habría correspondido a una tradicional práctica de complementariedad vertical (Aldunate et al. 2010: 346; Bittmann 1983: 149), la que pudo haber sido reorganizada dependiendo del contexto político, por ejemplo, durante el Tawantinsuyu o la colonización española.

Durante el siglo XVII, Cobija es referido como un territorio rico en recursos marinos, capaz de suministrar grandes cantidades de estos alimentos a tierras altas. Los pescadores nativos han sido encomendados a particulares, tributando en pescado o bien en plata, mientras ciertos sacerdotes reclaman la posesión de pesquerías personales (Aldunate et al. 2010: 344). De este modo, las comunidades nativas de Cobija fueron encomendadas a trabajar en pesquerías, modo principal de explotación de este punto de la costa durante la colonia temprana. Dichas pesquerías posibilitaron el abastecimiento de pescado a la provincia de Charcas, enriqueciendo a varios españoles gracias al tráfico en grandes caravanas de llamas:

"El puerto del mar del Sur más cercano a ella la ciudad de la Plata del Pirú, es el de Cobija, donde hacen las grandes pesquerías de congrio, liza, tollo y otros géneros de que se sustenta de pescado esta provincia de los Charcas [...] a la ciudad de la Plata llegan productos como pescado; hay mucho de la mar, saldo que se trae frescal, para las cuaresmas y entre año, tollo, congrio, liza, sardina, garcielo, corvina y otros muchos" (Pedro Ramírez de Águila, en Bittmann 1983: 147).

De esta manera, una amplia variedad de peces representaron la riqueza del área de Cobija en el contexto de la explotación colonial española. La corona se valió de los grupos de pescadores especialistas para comerciar con recursos que tradicionalmente fueron tributados o intercambiados en la lógica andina de la complementariedad.

"Porque en aquella costa se haze grandissima pesca de congrios, tollos, lisas, dorados, armados, vagres, pulpos y otros muchos géneros de pescados que salpresan, y del que lleuan grandes recuas de carneros a Potosí, Chuquisaca, Lipes, y a todas aquellas provincias de la tierra de arriba, porque es el trato principal de aquella tierra con que an enriquesido muchos" (Vásquez de Espinoza [1630] 1948: 618, en Castro et al. 2012: 109).

En las referencias más tempranas, escritas durante la segunda mitad del siglo XVI y primera década del XVII, el pescado es señalado como la base alimenticia de los grupos de pescadores de Cobija. Asimismo, señalan importantes prácticas pesqueras destinadas al consumo del recurso en la propia costa o bien al intercambio con Atacama (Tabla 6). Por el contrario, la recolección de mariscos no es referida como una práctica económica de relevancia, no existiendo ninguna mención por nosotros conocida sobre este tópico. Sin embargo, a medida que el siglo XVII avanza, el destino de los recursos pesqueros excede las dos áreas anteriores, siendo llevado a Charcas. Pero en paralelo a las menciones referidas, los primeros funcionarios coloniales describieron una economía nativa que además de basarse en la especialización pesquera, también se fundaba en la caza especializada de lobos marinos.

Los españoles observaron con asombro el aprovechamiento integral del lobo marino como recurso alimenticio, medio de transporte y materia prima para múltiples industrias artesanales (Castro et al. 2012: 109). Asimismo, la obtención de este preciado recurso económico habría estado a cargo de ciertos segmentos especializados en la caza de dichos mamíferos marinos, existiendo 


\begin{tabular}{|c|c|c|c|c|c|}
\hline Año & Estrategia & Recurso & Uso & Destino & Fuente \\
\hline 1558 & caza & lobos marinos & alimenticio & costa & Vivar \\
\hline 1558 & intercambio & balsa de lobo & transporte & costa & Vivar \\
\hline 1558 & artesanía & alquitrán & transporte & costa & Vivar \\
\hline 1581 & intercambio & pescado & alimenticio & Atacama & Lozano Machuca \\
\hline 1605 & caza & sangre de lobos & alimenticio & costa & Lizárraga \\
\hline 1605 & caza & cuero de lobo & vestimenta & costa & Lizárraga \\
\hline 1627 & pesca & Tollo & alimenticio & Charcas & Vásquez de Espinoza \\
\hline 1627 & pesca & lisa & alimenticio & Charcas & Vásquez de Espinoza \\
\hline 1627 & pesca & dorado & alimenticio & Charcas & Vásquez de Espinoza \\
\hline 1627 & pesca & armados & alimenticio & Charcas & Vásquez de Espinoza \\
\hline 1627 & pesca & vagres & alimenticio & Charcas & Vásquez de Espinoza \\
\hline 1627 & pesca & jureles & alimenticio & Charcas & Vásquez de Espinoza \\
\hline 1627 & pesca & atunes & alimenticio & Charcas & Vásquez de Espinoza \\
\hline 1627 & pesca & pulpos & alimenticio & Charcas & Vásquez de Espinoza \\
\hline 1627 & caza & cachalotes & & indeterminado & Vásquez de Espinoza \\
\hline 1627 & pesca & congrio & alimenticio & prov. inmediatas/Charcas & Vásquez de Espinoza \\
\hline 1644 & pesca & atún & alimenticio & Charcas & Arzobispo de La Plata \\
\hline 1684 & pesca & pescado & & & De la Peña Salazar \\
\hline XVIII & & ballenas & postes/asientos óseos & costa & Bauver \\
\hline 1716 & caza & lobos marinos & chozas/cuero & costa & Frezier \\
\hline 1716 & intercambio & maíz & alimenticio & costa & Frezier \\
\hline 1716 & intercambio & papas & alimenticio & costa & Frezier \\
\hline 1716 & intercambio & pescado & alimenticio & Atacama & Frezier \\
\hline 1716 & pesca & pescado & alimenticio & costa & Frezier \\
\hline 1786 & pesca & congrio & alimenticio & costa & Arze \\
\hline
\end{tabular}

Tabla 6. Menciones etnohistóricas sobre estrategias de subsistencia de los grupos de Cobija y la costa de Atacama durante el periodo Colonial (basado en Aldunate et al. 2010; Bittman 1983; Hidalgo 1983; Lizárraga 1968[1605]; Vivar 1966 [1558]).

además ciertos segmentos sociales especializados en la caza de toninas. Según los cronistas, los lobos eran cazados usando arpones de cobre, mientras éstos dormían tranquilamente en aquellos días sin viento (Vivar [1558] 1966: 10). Los cueros eran cortados, luego curtidos por el interior con una suerte de betún, para finalmente ser cosidos usando espinas de cactus. Para inflar la balsa, los nativos usaban una tripa de lobo a modo de manguera, la que estaba coronada con un tubo de pluma de ave marina. Cuando la balsa estaba suficientemente inflada, los nativos anudaban la tripa para que no escapara aire (Vi$\operatorname{var}[1558]$ 1966: 10).
En las tareas de preparación del cuero de los lobos marinos, el uso de minerales rojizos representó una práctica descrita por los propios observadores españoles, donde los artesanos nativos utilizaban un betún compuesto por sustancias orgánicas animales, vegetales y las mencionadas sustancias minerales rojizas. Con este compuesto procesaban el interior de los cueros de lobos cuidadosamente cortados. Estas prácticas artesanales fueron descritas minuciosamente durante el siglo XVI, refiriendo además a una producción excedentaria de balsas de cuero de lobo, destinada al intercambio con grupos costeros de otras latitudes. Asimismo, señalan que los propios 
segmentos especializados en la caza de lobos, serían aquellos que habrían trabajado los cueros y producido las balsas, representando segmentos de artesanos-cazadores especializados en ambas actividades:

"De la sangre del lobo y de resina de los cardones y de barro bermejo hacen una manera de betún que suple por alquitrán ceto [sic] ser colorado; y por de dentro alquitrán y brean el cuero." (Vi$\operatorname{var}[1558]$ 1966:11).

"Son muy grandes, y todos no matan los lobos sino los que lo usan y no usan otra pesquería sino matar lobos y comer la carne y de los cueros hacer balsas para sí y para vender" (Vivar [1558] 1966:10).

Adicionalmente, los lobos marinos representaron una importante fuente de alimentos, aprovechándose tanto la carne como la sangre (Tabla 6). De igual modo, con el cuero de estos animales fue confeccionada la vestimenta usada por los grupos de pescadores, situación señalada por los primeros españoles, mientras que referencias del siglo XVIII describen la construcción de chozas con este material. Lamentablemente, no hemos podido dar con referencias más precisas respecto a cómo estos bienes circularon al interior de las comunidades costeras en el contexto de prácticas de intercambio. Sin embargo, resulta bastante probable que los segmentos de artesanos-cazadores, especializados en el completo procesamiento de los lobos marinos, hayan tenido cierto protagonismo dentro de la organización económica de los pescadores tardíos observados durante el siglo XVI.

Los europeos también observaron el intercambio de productos marinos por productos agrícolas, generados por comunidades de agricultores y ganaderos del interior de la región. Las referencias coloniales señalan el intercambio de maíz y de topinambours (papas) por pescado del Pacífico, en el contexto del tráfico entre Atacama y Cobija durante el siglo XVIII temprano (Aldunate et al. 2010: 346). De igual forma, otras referencias señalan el intercambio de hojas de coca por pescados y mariscos, aunque mucho más al sur y ya en épocas republicanas (Aldunate et al. 2010: 346). Sin embargo, el arribo de vegetales cultivados a la costa representó una práctica económica precolombina, observada regularmente en los depósitos domésticos de los períodos tardíos e incluso anteriores (Sanhueza 1985), donde la complementariedad económica regional consideró también un excedente pesquero:

"El pueblo de Cobija está compuesto por unas cincuenta chozas de indígenas hechas con pieles de lobos marinos. Como el terreno es estéril, viven ordinariamente solo de pescado, un poco de maíz y de topinambours o papas, que les llegan de Atacama en trueque por el pescado". (Frezier 1716: 130, en Aldunate et al. 2010: 346).

En definitiva, las referencias etnohistóricas nos remiten fundamentalmente a grupos costeros de pescadores especializados en la captura de determinadas especies, quienes basaban la subsistencia grupal en el consumo de pescados. Asimismo, nos señalan interesantes prácticas de intercambio de este último recurso por vegetales cultivados, así como la probable tributación en pescado a los curacas de Atacama (antes de la encomienda de estos grupos en pesquerías). Adicionalmente, señalan segmentos sociales de artesanos especializados en el trabajo del cuero de lobo marino, materia prima con la que produjeron una amplia variedad de elementos, algunos de ellos destinados al intercambio como las propias balsas. Estos artesanos habrían sido además especialistas en la caza y faenamiento de los mencionados mamíferos marinos.

\section{* Los pescadores tardíos de Cobija}

Se ha postulado que las estrategias de subsistencia de los grupos costeros habrían correspondido a la caza, pesca y recolección, aproximadamente desde el 7000 AP en adelante (Llagostera 1992: 91). Sin embargo, en la costa arreica dichas estrategias habrían sido complementadas con recursos agrícolas a lo menos desde el formativo (Núñez 1971; Castro 2010; Urbina et al. 2011), desarrollándose un modo de vida marítimo con aportes agrarios condicionados por las comunidades de agricultores del interior, en la medida en que esta última práctica se fue consolidando (Núñez 1971: 20). De esta forma, la complementariedad económica correspondería a un proceso general del formativo costero, el cuál se habría intensificado notoriamente durante los períodos tardíos en diversas localidades (Núñez 1971; Sanhueza 1985; Aldunate et al. 2008). 
En paralelo, ciertos procesos regionales habrían determinado cambios económicos y sociales en la Atacama precolombina (Uribe y Adán 2005: 265). Uno de estos habría correspondido al paulatino asentamiento de comunidades de tierras altas atacameñas en porciones inferiores de la cuenca del Loa, generando asentamientos en Quillagua y Caleta Huelén durante el Intermedio Tardío, en el contexto de un fuerte aumento demográfico (Uribe 2002: 24-27). El mayor asentamiento en localidades relativamente cercanas habría posibilitado rutas caravaneras "cortas" (Núñez y Dillehay 1995: 165), aumentando la interacción entre los grupos asentados en el Loa y la costa. En el área de Cobija lo anterior aconteció desde el Formativo en adelante, no obstante lo cuál presentó una notoria intensificación desde el Intermedio Tardío, observándose prácticas complementarias que enriquecieron las estrategias marítimas tradicionales con recursos producidos por las comunidades del interior de Atacama (Aldunate et al. 2008; Castro 2001). El Tawantinsuyu pudo haber modificado este panorama con transformaciones económicas relacionadas a la reorganización jerárquica decimal de las comunidades provinciales (Murra 1999), al modelo de tripartición social (Acuto 1999), y al consecuente redireccionamiento de caravanas (Núñez y Dillehay 1995: 165). Sin embargo, en el área de Cobija antes de la encomienda en las denominadas pesquerías, los grupos de pescadores generaban un excedente pesquero destinado tradicionalmente a otras localidades de la región (Vivar [1558] 1966:12).

Consideramos que los distintos contextos históricos acontecidos en la costa de Atacama influyeron en la intensidad y organización con que fueron desarrolladas las estrategias tradicionales de subsistencia (caza, pesca y recolección marítima), no debiéndoselas considerar estáticas e invariables. Las actividades económicas cotidianas generaron depósitos domésticos compuestos por patrones arqueológicos dinámicos (Lynne 1997; Allison 1998; Souvatzi 2008), los que presentaron particularidades tardías en comparación con las prácticas de caza, pesca y recolección observadas en depósitos de otros períodos. Lo anterior resultó notorio en comparación con los depósitos domésticos generados durante el Arcaico, conformados por altas frecuencias de restos óseos de mamíferos y de instrumentos líticos de bordes filosos con microhuellas de corte y frecuencias variables de restos ictiológicos y casos puntuales de vegetales cultivados
(García-Albarido 2012). No obstante, en el área de Cobija la cabal comprensión de las transformaciones económicas requiere de estudios detallados sobre depósitos domésticos de períodos poco conocidos como el período Formativo.

De todas maneras, la existencia de pescadores tardíos especializados, dotados de una tecnología que les permitió obtener un excedente pesquero regular, cambiando las intensidades con que desarrollaron cada una de las estrategias tradicionales de subsistencia marina, resulta altamente coherente con los depósitos domésticos analizados por nosotros en el área de Cobija. Las actividades cotidianas de subsistencia generaron altas frecuencias de restos ictiológicos, depositados de modo bastante regular en estratos domésticos, donde además se observaron significativas asociaciones con lienzas y cordeles para pescar, anzuelos metálicos e instrumentos líticos pesqueros. Los depósitos tardíos sugieren una fuerte especialización en la captura del jurel, así como en la utilización del algodón para producir líneas y redes de pesca, evidencias textiles depositadas en altas frecuencias en asociación con pesas para anzuelos compuestos y anzuelos metálicos. Nuevamente, estos depósitos originados en actividades pesqueras demuestran escasas evidencias de talla lítica e instrumentos líticos, sugiriendo que durante las ocupaciones tardías los bordes activos filosos utilizados en actividades de corte y procesamiento no tuvieron el mismo protagonismo que en los depósitos arcaicos del área (García-Albarido 2012). De este modo, las evidencias arqueológicas y etnohistóricas apuntan a economías pesqueras, las mismas que luego serían observadas y aprovechadas por los conquistadores españoles.

En este sentido, el desarrollo metalúrgico costero aplicado a la fabricación de instrumental pesquero durante dichos períodos (p.e., anzuelos y barbas de arpón), también ha sido interpretado como una especialización técnica relacionada a la intensificación de las prácticas pesqueras (Salazar et al. 2010a: 24; Salazar et al. 2010b: 16). Esta situación ha sido registrada al norte de Cobija, específicamente entre Punta Atala y Paquica, donde las comunidades costeras desarrollaron actividades metalúrgicas destinadas a producir anzuelos (Salazar et al. 2010a: 39). De esta forma, resulta probable que estas comunidades hayan orientado sus actividades económicas a la producción de un excedente pesquero a mayor escala desde los 
períodos tardíos precolombinos, destinado a la tributación o intercambio con las comunidades del interior de Atacama (Salazar et al. 2010a). La especialización e intensificación de las actividades pesqueras, en desmedro de las actividades de cacería, también ha sido registrada en ocupaciones alfareras de otras localidades costeras del desierto (Núñez y Moragas 1977: 48).

Sin lugar a dudas, la complementariedad de los recursos del interior con aquellos generados por las estrategias costeras correspondió a un fenómeno generalizado en la costa desértica desde épocas muy anteriores a los períodos tardíos (Núñez 1971; Sanhueza 1985; Urbina et al. 2011). Esta habría permitido la obtención de una amplia gama de recursos, desde productos agrícolas hasta objetos metálicos de status, como los cuchillos, hachas y placas (Salazar et al. 2010a: 39; Urbina et al. 2011: 70). Por ejemplo, la economía doméstica de los grupos formativos de Punta Patache se habría basado en la recolección de moluscos y en la pesca, incorporando en menor frecuencia el consumo de recursos del interior (Urbina et al. 2011: 70). Por su parte, el algodón representó el único vegetal cultivado evidenciado en Cobija 10 (Moragas 1980: 165), mientras que ciertos vegetales como la quínoa han sido recuperados en otros contextos formativos en Caleta Huelén (Núñez 1971). Por el contrario, los restos de vegetales cultivados han presentado altas frecuencias en depósitos de períodos tardíos. Por ejemplo, en Los Verdes se han obtenido abundantes restos de maíz, algodón, calabaza, algarrobo, quínoa y coca (Sanhueza 1985: 55). En Cobija hemos observado una significativa asociación entre ocupaciones de períodos tardíos y vegetales cultivados o vegetales nativos de otras localidades (Castro 2010: 41), situación no observada en depósitos arcaicos. Esto resulta coherente con el incremento del cultivo en nuevos espacios, por ejemplo del maíz, así como de la intensificación de la molienda y la construcción de nuevos silos para almacenamiento desde el Intermedio Tardío en Atacama (Uribe y Adán 2005: 266-267).

Si bien varios investigadores coinciden en que los grupos de pescadores locales habrían participado en una dinámica económica compleja con poblaciones del interior, alcanzando su máxima intensidad durante los períodos tardíos (Núñez 1971: 20; Sanhueza 1985: 59), evaluar la intensificación tardía del consumo de vege- tales en la costa y pescado en el interior, requerirá del análisis sistemático de estos tópicos en contextos domésticos de otros períodos alfareros, tanto en el área de Cobija como en las localidades con las que estableció dicha dinámica.

Por otra parte, los observadores europeos no mencionan el hecho de que las poblaciones costeras realizaran recolecciones de mariscos, exceptuando una referencia a mariscos secos durante épocas republicanas (Aldunate et al. 2010: 346), quizás por haber estado más interesados en el potencial económico del excedente pesquero generado por las comunidades tardías. De igual modo, si bien la recolección de moluscos en el intermareal rocoso correspondió a una dilatada estrategia de subsistencia, basada en la obtención de recursos de fácil acceso (Peña et al. 2013), los depósitos domésticos tardíos demostraron prácticas de menor intensidad en relación, por ejemplo, a los depósitos arcaicos del área. Las causas resultan complejas de conocer, relacionándose quizás con el desarrollo de estrategias de subsistencia más diversificadas y regulares (más especializadas y menos oportunistas) y/o a una menor disponibilidad de recursos por depredación.

Por otra parte, los españoles observaron importantes cacerías de mamíferos marinos, donde los lobos marinos fueron utilizados tanto para alimentación como para producir vestimentas, viviendas y medios de transporte. Ahora bien, en los depósitos domésticos tardíos las evidencias relacionadas a esta práctica correspondieron a restos óseos e instrumentales. Los primeros nos remitieron a prácticas selectivas, orientadas principalmente al apresamiento de lobos marinos y en menor medida guanacos, siendo depositados en frecuencias variables aunque en términos generales bastante bajas. En estos eventos también se depositaron instrumentos con bordes filosos tallados en sílice, algunos de los cuales fueron utilizados para cortar y procesar los animales apresados, aunque también en frecuencias notoriamente bajas. En estos eventos ocupacionales, la talla lítica tampoco representó una actividad de importancia, observándose una importante transformación tecnológica al desaparecer casi toda la industria de guijarros tallados (p.e., choppers), íntimamente relacionada al probable procesamiento de mamíferos en depósitos de períodos anteriores (García-Albarido 2012). 
En consecuencia, los sitios estudiados no presentaron evidencias de cacerías intensivas como una de las principales causas de conformación del depósito arqueológico. Sin embargo, determinados depósitos representan una excepción a lo recién señalado, mostrando mayores frecuencias de restos óseos, desechos de talla, instrumentos y microhuellas de corte. Este patrón depositacional, generado en eventos de caza y procesamiento de mamíferos marinos, también ha sido registrado en otros sectores de la costa arreica: en Punta Patache han sido identificados depósitos generados por el faenamiento de lobos marinos (Urbina et al. 2011: 70). Las referencias históricas señalan la existencia de segmentos especializados en la caza y faenamiento de lobos marinos, quienes también pudieron haber generado dichos depósitos. En consecuencia, éstos podrían explicarse simplemente como el producto de un área de actividad particular en el asentamiento, o bien, como el producto de ocupaciones de segmentos sociales especializados en estas actividades. Por su parte, los componentes orgánicos de los instrumentos de caza (p.e., barbas óseas para arpón) resultaron bastante escasos aunque significativamente asociados a los depósitos anteriores.

La estructura tecnológica, representada primordialmente por los distintos tipos de instrumentos líticos y sus funcionalidades, también demostró notorios cambios respecto a la observada en depósitos arcaicos del área (García-Albarido 2012). En términos generales, es posible señalar que en esta parte de la costa los grupos dejaron de tallar una serie de instrumentos relacionados con actividades de cacería y procesamiento de animales. De esta manera, durante dichos períodos virtualmente desapareció el instrumental tallado en guijarros de andesita (choppers, choppingtools y unifaces), mientras que los instrumentos de bordes filosos en sílice también fueron tallados en frecuencias notoriamente menores (bifaces, raspadores y raederas), resultando también las puntas y sus preformas menos frecuentes y más pequeñas (GarcíaAlbarido 2012: 116). De igual modo, las microhuellas relacionadas al procesamiento de presas, específicamente las microhuellas de corte y raspado, redujeron drásticamente sus frecuencias de aparición en los depósitos tardíos, observándose una escasa asociación con adherencias orgánicas de probable origen animal (García-Albarido 2012: 117). En consecuencia, las evidencias señaladas también sugirieron depósitos domésticos originados por grupos dedicados fuertemente a actividades pesqueras.
Sin embargo, la estructura de la tecnología lítica demostró ciertas continuidades a lo largo de la secuencia. Durante los períodos tardíos en las tierras altas de Atacama, la intensificación de las prácticas agrícolas ha quedado reflejada en los instrumentos líticos relacionados, como el aumento de palas líticas, azadas, morteros y manos de moler (Uribe y Carrasco 1999). En Cobija esta transformación no aconteció, no contándose con herramientas líticas de uso agrícola, mientras los instrumentos posibles de utilizar en el procesamiento de vegetales, específicamente los morteros líticos, resultaron muy escasos. A pesar de los recurrentes restos de fibras, cactáceas, algodón y prosopis, además de maíz, chañar y cucurbitaceae, solamente fueron identificados casos excepcionales de guijarros e instrumentos de bordes filosos con estrías y adherencias orgánicas verdosas, posiblemente de origen vegetal. En este sentido, los instrumentos y sus modos tradicionales de utilización no reflejaron un importante cambio en relación a la producción y procesamiento generalizado de recursos vegetales en la costa.

Del mismo modo, los guijarros sin tallar continuaron siendo utilizados en tareas relacionadas al frotado de materiales blandos durante los períodos tardíos. Al igual que en épocas anteriores, ciertos depósitos los presentaron y otros no, evidenciando en numerosos casos adherencias orgánicas amarillas de probable origen animal, mientras que en algunos de los sobadores éstas se relacionaron también con adherencias minerales rojizas. Los españoles describieron cómo el interior de los cueros de lobo marino era preparado utilizando una suerte de betún compuesto por sustancias de origen animal, vegetal y mineral (Vivar [1558] 1966: 11). La asociación entre óxido de hierro y trabajo sobre pieles se ha registrado en varios análisis funcionales líticos, señalándose propiedades antisépticas y secantes que favorecen el proceso de secado (Ríos et al. 2002: 148). Consideramos que los frecuentes sobadores registrados en los depósitos tardíos de Cobija fueron probablemente usados en labores artesanales de curtido de cuero, las que habrían tenido fines diversos entre los que destaca la producción de balsas de cuero de lobo (García-Albarido 2012: 123). De todas formas, la distribución en depósito de estas evidencias y su relación con segmentos de cazadores-artesanos especializados en la caza y procesamiento del lobo marino, continúa representando un problema de estudio abierto a nuevos datos. 


\section{$*$ Conclusiones}

Los depósitos domésticos estudiados han sugerido matices tardíos a la consideración de que las prácticas económicas de los grupos costeros pueden reducirse a la caza, pesca y recolección, sin transformaciones históricas derivadas de contextos regionales específicos de interacción (Núñez 1971; Núñez y Moragas 1977; Sanhueza 1985; García-Albarido 2012). De este modo, la economía doméstica local sugiere una mayor diversificación y dependencia, en paralelo a las tres actividades tradicionales, demostrando una intensa y regular base pesquera, la misma que posteriormente fue descrita por los españoles. Consideramos que esta situación se explica por un mayor nivel de integración regional en Atacama, caracterizado desde el Intermedio Tardío en adelante por intensas prácticas de caravaneo e intercambio regional (Núñez 2006: 222), así como por el incremento de la producción agrícola excedentaria en las comunidades de tierras altas (Uribe y Adán 2005: 266-267).

La mayor diversificación económica tardía incluyó el suministro regular de vegetales cultivados a Cobija, evidenciándose también minería del cobre y efímeros depósitos metalúrgicos, probablemente vinculados a una factura local, doméstica y expeditiva de anzuelos de cobre. Por su parte, la intensa utilización pesquera de redes y líneas de algodón, hizo depender la subsistencia costera en un recurso probablemente cultivado y trasladado del interior, aunque no podemos descartar su cosecha en la propia costa al considerar ciertos topónimos (Núñez y Moragas 1977: 38; García-Albarido 2012: 128) eventualmente trasladado en embarcaciones desde los valles ariqueños. Estamos seguros de que dicha diversificación y dependencia constituyen fenómenos originados durante el período Formativo. Sin embargo, su intensificación durante los períodos tardíos debiera ser evaluada en comparación con depósitos domésticos formativos. No obstante lo anterior, resulta evidente en relación con los depósitos arcaicos del área (Núñez 1971; Sanhueza 1985; Aldunate et al. 2008; García-Albarido 2012).
En definitiva, la fuerte dependencia en la caza y recolección marina observada en las ocupaciones arcaicas de Cobija, habría disminuido en función de una mayor integración económica con el resto de Atacama durante los períodos tardíos. En este contexto, los pescadores camanchacas probablemente generaron un excedente pesquero destinado a las diversas comunidades de la región, desarrollando importantes y regulares prácticas basadas en instrumentos especializados, como por ejemplo redes de algodón y anzuelos metálicos, cabiendo la posibilidad de cierta dependencia respecto de la primera materia prima. En este contexto, habrían existido segmentos de especialistas de artesanos-cazadores, quienes habrían estado a cargo de la fundamental industria del lobo marino, destinada a abastecer la demanda de los pescadores respecto al principal medio productivo: las balsas de cuero. La casi total desaparición de los instrumentos con bordes filosos tallados en cantos rodados de andesita, usados para cortar de manera muy frecuente durante el periodo Arcaico, sugiere tareas de procesamiento más acotadas. Por el contrario, la amplia distribución tardía de los sobadores usados para frotar materiales blandos evidenció extendidas actividades probablemente relacionadas al trabajo del cuero, lo que invita a tratar este problema con cautela. De todas maneras, los depósitos domésticos tardíos señalan una fuerte complementariedad económica regional, representada por el regular acceso a vegetales en esta parte de la costa y la probable generación de excedentes pesqueros, sobre la base de complejos vínculos con los caciques de Atacama. Los españoles explotarían hábilmente este tradicional excedente productivo desde fines del siglo XVI en adelante, entregando en encomienda a los grupos de pescadores tardíos de Cobija.

Agradecimientos Al proyecto Fondecyt $\mathrm{N}^{\circ} 1100951$ "Del Período Formativo al Tardío en la Costa de Antofagasta. Cronología e interrelaciones con las Tierras Altas", y a su equipo de trabajo: investigadores, tesistas, memoristas y personal de apoyo. A la arqueóloga Daniela Valenzuela por su apoyo. A los revisores y editores de este manuscrito por sus comentarios. 


\section{* Referencias citadas}

ACUTO, F. 1999. Paisaje y dominación: la constitución del espacio social en el imperio Inka. En Sed Non Satiata. Teoría Social en la Arqueología Latinoamericana Contemporánea. A. Zarankin y F. Acuto (Eds.). Ediciones del Tridente, Buenos Aires.

ALDUNATE, C., V. CASTRO y V. VARELA. 2008. San Bartolo y Cobija: testimonios de un modo de vida minero en las tierras altas y la costa de Atacama". Estudios Atacameños 35: 97-117.

2010. Los Atacamas y el pescado de Cobija. Revista Chungara 42 (1): 341-347.

ALLISON, P. 1998. The Household in Historical Archaeology. Australasian Historical Archaeology 16: 16-29.

ANDREFSKY, W. 2008. An Introduction to Stone Tool Life History and Technological Organization. En Lithic Technology: measures of production, use and curation. W. Andrefsky (Ed.), pp. 3-22. Cambridge University Press, New York.

ASCHERO, C. [1974] 1983. Ensayo para una clasificación morfológica de artefactos líticos aplicada a estudios tipológicos comparativos. Informe inédito a CONICET.

BERENGUER, J. 2004. Caravanas, interacción y cambio en el desierto de Atacama. Sirawi Ediciones, Santiago.

BITTMANN, B. 1983. Cobija: Panorama etnohistórico en relación a los informes del Dr. José Agustín de Arze. Chungara 10: 147-153.

CARRASCO, C. 2002. Las industrias líticas de Quillagua durante el Periodo Formativo, en el contexto del Norte Grande. Estudios Atacameños 22:33-57.

CARTAJENA, I. 2008. Restos Arqueofaunísticos Cobija 24. Informe para Proyecto Fondecyt 1050991. El "desierto" costero y sus vinculaciones con las tierras altas. De Cobija a Calama. Manuscrito en posesión de los autores.

CASES, B. 2009. Textiles costeros de Cobija 1 norte y Caleta del Fierro 2. Informe para Proyecto Fondecyt 1050991 "El "desierto" costero y sus vinculaciones con las tierras altas. De Cobija a Calama". Manuscrito en posesión de los autores.

CASTRO, V. 2001. Atacama en el tiempo. Territorios, identidades, lenguas (provincia El Loa, II Región). Anales de la Universidad de Chile VI (13): 27-70.

2010. Sabores Ancestrales. Caza, Recolección y Producción de Alimentos en el Norte Prehispánico. En Historia y Cultura de la Alimentación en Chile. Miradas y saberes sobre nuestra culinaria. C. Sciolla (Ed.), pp. 27-62. Catalonia, Santiago.

CASTRO, V., C. ALDUNATE y V. VARELA. 2012. Paisajes Culturales de Cobija, Costa de Antofagasta, Chile. Revista Chilena de Antropología 26: 97-128.

CHECURA, J. 1977. Funebria Incaica en el cerro Esmeraldas (Iquique, I Región). Estudios Atacameños 5: 127-144.

CHERKINSKY, A. 2011. Radiocarbon Analysis Report, UGAM 8823. Center for Applied Isotope Studies, University of Georgia.

CRUZ, J. y L. BRAVO. 1980. Cobija Sur-1, sitio de ocupación temprana en la costa de Cobija, II región Chile. Cobija: Proyecto de investigaciones interdisciplinarias en la costa centro sur andina (Chile). Universidad del Norte, Antofagasta.

DE SOUZA, P. 2003. Tecnología lítica y sistemas de asentamiento de los cazadores recolectores del Arcaico Temprano y Medio en la cuenca superior del río Loa. Memoria para optar al Título de Arqueólogo. Departamento de Antropología, Facultad de Ciencias Sociales, Universidad de Chile, Santiago.

DURING, B. y A. MARCINIAK. 2006. Households and communities in the central Anatolian Neolithic. Archaeological Dialogues 12 (2): 165-187. Cambridge University Press.

EARLE, T. 1994. Wealth Finance in the Inca Empire: Evidence of the Calchaquí Valley, Argentina. American Antiquity 59 (3): 443-460.

ELÍAS, A. 2008. Estrategias tecnológicas y variabilidad de los conjuntos líticos de las sociedades de los Períodos Tardío y TardíoInca en Antofagasta de la Sierra (Prov. de Catamarca, Puna Meridional argentina) y Doncellas (Prov. de Jujuy, Puna Septentrional argentina)". Comechingonia 1: 43-72.

FERNÁNDEZ, L. 2010. Grupos domésticos y espacios habitacionales en las Tierras Bajas mayas durante el periodo Clásico. Dissertation zur Erlangung der Würde des Doktors der Philosophie. Der Universität Hamburg vorgelegt von aus Mérida, Yucatán, México. Hamburgo.

FIELD, J., P. KIRCH, K. KAWELU, y T. LADEFOGED. 2010. Households and Hierarchy: Domestic Modes of Production in Leeward Kohala, Hawai'i Island. The Journal of Island and Coastal Archaeology 5 (1):52-85.

GARCÍA-ALBARIDO, F. 2012. Estrategias de subsistencia en Cobija durante el Periodo Intermedio Tardío y el Tawantinsuyu. Aproximación 
desde la funcionalidad de los instrumentos líticos. Memoria para optar al título de Arqueólogo. Facultad de Ciencias Sociales, Universidad de Chile, Santiago.

HOCSMAN, S. 2006. Tecnología lítica en la transición de cazadores recolectores a sociedades agropastoriles en la porción meridional de los Andes Centro Sur. Estudios Atacameños 32: 59-73.

HOOD, D. 2007. Radiocarbon Dating Results For Samples COBıN-1B1, $C O B 1 N-1 B 2, C O B 1 N-2 B, C O B 1 N-5$. Beta Analytic Inc. Florida (Ms).

2008. Radiocarbon Dating Results For Samples COBI-24C2NIMl, $\mathrm{COBI}_{24} \mathrm{C}_{3} \mathrm{NI}_{2} \mathrm{M2}_{2}$. Beta Analytic Inc. Florida (Ms).

JACKSON, D. 2003. Modelos cognitivos e indicadores de aprendizaje en tecnología lítica: algunas aproximaciones. En Actas del XVI Congreso Nacional de Arqueología Chilena (Tomé), pp. 47-53. Museo de Historia Natural de Concepción, Escaparate Ediciones, Concepción.

Mc CORMAC, F.G., A.G HOGG, P.G. BLACKWELL, C.E. BUCK, T.F.G. HIGHAM y P.J. REIMER. 2004. SHCalo4 Southern Hemisphere calibration, o-11.o cal kyr BP. Radiocarbon 46: 10871092.

MARTÍNEZ, K. 2002. Actividades concretas y su organización espacial en el interior del yacimiento del paleolítico medio del Abric Romaní (Capellades, Barcelona): análisis funcional de objetos remontados. En Análisis Funcional: su aplicación al estudio de sociedades prehistóricas. I. Clemente, R. Risch y J. F. Gibaja (Eds), pp. 111-120. BAR International Series 1073.

MÉNDEZ, C. 2007. Tecnología lítica en el Camino Inca, norte de Chile. Estudios Atacameños 33: 39-57.

MORAGAS, C. 1980. Túmulos funerarios en la costa sur de Tocopilla (Cobija), II Región. Revista Chungara 9: 152-173.

MURRA, J. [1955] 1999. La organización económica del Estado Inca. Siglo XXI, México.

NASH, D. 2009. Household Archaeology in the Andes. Journal of Archaeological Research 17: 205-261.

NÚÑEZ, L. 1971. Secuencia y cambio en los asentamientos humanos de la desembocadura del río Loa en el Norte de Chile. Boletín de la Universidad de Chile 112:3-25.

2006. La orientación minero-metalúrgica de la producción atacameña y sus relaciones fronterizas. En Esferas de interacción prehistóricas y fronteras nacionales modernas: Los Andes Sur Centrales. H. Lechtman (Edit.), pp. 205-220. Instituto de Estudios Peruanos.
NÚÑEZ, L. y C. MORAGAS. 1977. Ocupación con cerámica temprana en la secuencia del distrito de Cáñamo (costa desértica, norte de Chile). Estudios Atacameños 5: 21-49.

NÚÑEZ, L. y T. DILLEHAY. 1995. Movilidad Giratoria, Armonía Social y Desarrollo en los Andes Meridionales: Patrones de Tráfico e Interacción Económica. Ensayo. Segunda Edición. Universidad Católica del Norte, Antofagasta.

LLAGOSTERA, A. 1992. Early occupations and the emergence of fishermen on the Pacific coast of South America. Andean Past 3: 87-109.

LIZÁRRAGA, R. [1605] 1968. Descripción breve de toda la tierra del Perú, Tucumán, Río de La Plata y Chile. Biblioteca de Autores Españoles, tomo 216, pp. 1-213. Ediciones Atlas, Madrid.

LOZANO MACHUCA, J. [1581] 1992. Carta del factor de Potosí JLM (al Virrey del Perú Don Martín Enriquez) en la que da cuenta de cosas de aquella villa y de la mina de los Lípez (año 1581). Transcripción de J.M. Casassas. Estudios Atacameños 10 : 30-34.

LYNNE, E. 1997. Household Archaeology at the Scowlitz site, Fraser Valley, B.C..Tesis para optar al grado de Magíster en Arte, Universidad de Columbia Británica.

OLGUíN, L. 2011. Informe Arqueofauna Sitios Guasilla 2 y Mantos de la Luna 4. Informe para Proyecto Fondecyt 1100951: "Del periodo formativo al tardio en la costa de Antofagasta: Cronología e interrelaciones con las tierras altas". Manuscrito en posesión de los autores.

ORQUERA, L. y E. PIANA. 1986. Normas para la descripción de objetos arqueológicos de piedra tallada. Contribución científica, Publicación Especial 1. Ushuaia, CADIC.

PEÑA, I., L. OLGUIN, P. FIBIA, V. CASTRO y M. SALAVERRY. 2013. Aprovechamiento de aves marinas durante el Holoceno Medio en el litoral árido del norte de Chile. Revista Chilena de Historia Natural 86 (en prensa).

PÉREZ, S. 2008. La organización de la tecnología lítica en el noroeste argentino. Aproximación a través de experimentación, análisis tecno-morfológico y de microdesgaste por uso de palas y/o azadas líticas. Comechingonia 3:186-222.

RÍOS, J., I. ORTEGA, J. IBÁÑEZ y J. GONZÁLES. 2002. El aporte del análisis funcional para el conocimiento del yacimiento auriñaciense de Barbas III. Primeros resultados. En Análisis Funcional: su aplicación al estudio de sociedades prehistóricas. I. Clemente, R. Risch y J. Gibaja (Eds.), pp. 141-150. BAR International Series 1073. 
SALAZAR, D., V. FIGUEROA, B. MILLE, D. MORATA y H. SALINAS. 2010a. Metalurgia prehispánica en las sociedades costeras del norte de Chile (quebrada Mamilla, Tocopilla). Estudios Atacameños 40: 23-42.

SALAZAR, D., V. CASTRO, J. MICHELOW, H. SALINAS, V. FIGUEROA y B. MILLE. 2o1ob. Minería y metalurgia en la costa arreica de la región de Antofagasta, norte de Chile. Boletín del Museo Chileno de Arte Precolombino 15 (1): 9-23.

SANHUEZA, J. 1985. Poblaciones tardías en "Playa Los Verdes" costa sur de Iquique I Región- Chile. Chungara 14: 45-6o.

SANTANDER, B. 2011. Informe de análisis de artefactos óseos recuperados en los sitios Cobija 1 norte y Copaca 1. Informe para Proyecto Fondecyt 1100951: "Del periodo formativo al tardío en la costa de Antofagasta: Cronología e interrelaciones con las tierras altas". Manuscrito en posesión de los autores.

SOUVATZI, S. 2008. A Social Archaeology of Households in Neolithic Greece: An Anthropological Approach. Cambridge Studies in Archaeology, Cambridge University Press.

STANISH, C. 1997. Nonmarket Imperialism in the Prehispanic Americas: the Inca ocupation of the Titicaca basin. Latin AmericanAntiquity 8(3): 195-216.

STUIVER M. y P. REIMER. 1993. Extended ${ }^{14} \mathrm{C}$ Data Base and Revised Calib $3.0^{14} \mathrm{C}$ Age Calibration Program. Radiocarbon 35 (1): 215-230.

TORRENCE, R. 1989. Tools as optimal solutions. En Time, Energy and Stone Tools. R. Torrence (Ed.), pp. 1-6. Cambridge University Press, New York.

TORRES, X. 2008. Estudio de los restos ictioarqueológicos de los sitios Cobija 1 Norte y Cobija 24. Localidad de Cobija, Región de Antofagasta. Informe para Proyecto Fondecyt 1050991 "El "desierto" costero y sus vinculaciones con las tierras altas. De Cobija a Calama". Manuscrito en posesión de los autores.

TRINGHAM, R. 2001. Household Archaeology. International Encyclopedia of the Social y Behavioral Sciences. Elsevier Science.

URBINA, S., L. ADÁN, C. MORAGAS, S. OLMOS y R. AJATA. 2011. Arquitectura de asentamientos de la costa de Tarapacá, norte de Chile. Estudios Atacameños 41:63-96.

URIBE, M. 2002. Sobre alfarería, cementerios, fases y procesos durante la prehistoria tardía de Atacama (800-1600 d.C.). Estudios Atacameños 21: 7-31

2009. El período Formativo de Tarapacá y su cerámica: Avances sobre complejidad social en la costa del Norte Grande de Chile (900 AC -80o DC). Estudios Atacameños 37: 5-27.

URIBE, M. y C. CARRASCO. 1999. Tiestos y piedras talladas de Caspana: la producción alfarera y lítica en el Periodo Tardío del Loa Superior. Estudios Atacameños 18: 55-71.

URIBE, M. y L. ADÁN. 2005. Arqueología e Historia... Cultura y evolución social en el desierto de Atacama (900-170od.C.). En Actas del XVI Congreso Nacional de Arqueología Chilena (Tomé), pp. 263-274. Museo de Historia Natural de Concepción, Escaparate Ediciones, Concepción.

VARELA V. 2009. La cerámica Arqueológica de Taltal. Taltalia 2: 119-128.

VIVAR, J. 1966 (1558). Crónica y relación copiosa y verdadera de los reinos de Chile. Edición facsimilar y a plana del Fondo Histórico y Bibliográfico José Toribio Medina, Tomo II, Santiago.

ZANOLLI C. 2005. Tierra, encomienda e identidad: Omaguaca (15401638). Sociedad Argentina de Antropología, Buenos Aires. 